Supporting information for

\title{
Xylaridines C and D, Unusual Thiopyranodipyridine Alkaloids from Fungus Xylaria longipes
}

Jing Li, Lan-Qing Li, ${ }^{\S}$ Xian Wang, ${ }^{\S}$ Tao Feng ${ }^{*} \dagger, \star$ and Ji-Kai Liu ${ }^{*}, \dagger$,

${ }^{\dagger}$ School of Pharmaceutical Sciences, South-Central University for Nationalities, Wuhan 430074, China

*The Modernization Engineering Technology Research Center of Ethnic Minority Medicine of Hubei Province, School of Pharmaceutical Sciences, South-Central University for Nationalities, Wuhan 430074, China

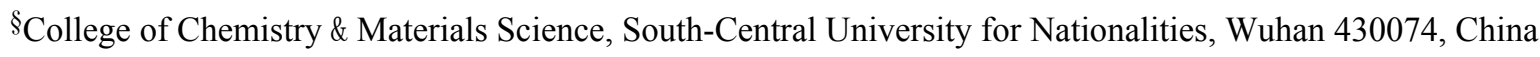

*Correspondence author: wenxuanwang@tom.com (W. X. Wang); tfeng@mail.scuec.edu.cn (T. Feng); liujikai@mail.scuec.edu.cn (J. K. Liu)

\section{List of Supporting Information}

\section{Experimental Section}

1.1. General experimental procedures

1.2. Fungal material

1.3. Fermentation, extraction, and isolation

1.4. ECD calculation of 1 and 2

1.5. Antibacterial assay

1.6. Cytotoxicity assay

2. NMR spectra, MS and CD spectra of xylaridine $C$ (1) and xylaridine $D(2)$

2.1. NMR spectra, HRESIMS and CD spectra of xylaridine $C$ (1)

2.2. NMR spectra and HRESIMS of xylaridine D (2)

2.3. ${ }^{1} \mathrm{H}$ NMR spectra for the mixture of (-)-2 and meso-2 
2.4. 1H NMR spectra for (+)-2, the mixture of (-)-2 and meso-2, and 2

\section{The ECD calculation data of xylaridine C (1) and xylaridine D (2)}

\section{Experimental Section}

1.1. General experimental procedures. HRESIMS spectra were recorded on Q Exactive Obitrap mass spectrometer (ThermoFisher Scientific, USA). Optical rotations were measured with a Rudoph AUTOPOL IV polarimeter. UV data were afforded with a UH5300 UV-VIS Double Beam Spectrophotometer. CD spectra were recorded with an Applied Photophysics spectrometer. Melting points were obtained on an X-4 micro melting point apparatus. IR spectra were obtained with a Shimadzu Fourier Transform Infrared Spectrometer using KBr pellets. 1D and 2D spectra were run on a Bruker Avance III $600 \mathrm{MHz}$ spectrometer with TMS as an internal standard. Chemical shifts $(\delta)$ were expressed in ppm with reference to the solvent signals. Column chromatography (CC) was performed on silica gel (200-300 mesh, Qingdao Marine Chemical Ltd., Qingdao, People's Republic of China), RP-18 gel (20-45 $\mu \mathrm{m}$, Fuji Silysia Chemical Ltd., Japan), and Sephadex LH-20 (Pharmacia Fine Chemical Co., Ltd., Sweden). Medium Pressure Liquid Chromatography (MPLC) was performed on a Biotage SP1 System, and columns packed with RP-18 gel. Preparative High Performance Liquid Chromatography (prep-HPLC) was performed on an Agilent 1260 liquid chromatography system equipped with a Zorbax SB-C18 column (Agilent, $5 \mu \mathrm{m}, 9.4 \mathrm{~mm} \times 150 \mathrm{~mm}$ ) and a DAD detector. Fractions were monitored by TLC (GF 254, Qingdao Haiyang Chemical Co., Ltd. Qingdao, China), and spots were visualized by heating silica gel plates sprayed with $10 \% \mathrm{H}_{2} \mathrm{SO}_{4}$ in EtOH. All solvents were analytical grade.

1.2. Fungal material. The fungus Xylaria longipes was collected at Ailao Moutain, Yunnan 
Province of China in 2013 and were identified by Prof. Yu-Cheng Dai (Beijing Forestry University). The strain is deposited at South-Central University for Nationalities, China (No. CGBWSHF00219).

1.3. Fermentation, extraction, and isolation. This strain was cultured on PDA medium for 8 days, and then was cut into small pieces to incubate on solid rice medium $\left(100 \mathrm{~g}\right.$ rice, $0.01 \% \mathrm{CuSO}_{4}, 1 \%$ peptone, and $100 \mathrm{~mL}$ tap water for each $500 \mathrm{~mL}$ Erlenmeyer flask, the total weight of rice was $10 \mathrm{~kg}$ ) to culture for further 30 days at $25^{\circ} \mathrm{C}$.

The fermented rice medium was broken up into small pieces and extracted with $30 \mathrm{~L}$ ethyl acetate for 3 times. The extract was concentrated under vacuum with rotary evaporator to yield $80.0 \mathrm{~g}$ dark brown residue. The extract ( $80 \mathrm{~g}$ ) was subjected to $\mathrm{CC}$ on silica gel (petroleum ether/ ethyl acetate, step gradient elution 1:0, 20:1, 10:1, 5:1, 2:1, 1:1, 0:1) to obtain seven fractions (A-G). Fr.F (10.0 g) was subjected to CC on silica gel (petroleum ether/ ethyl acetate, step gradient elution 15:1, 10:1, $5: 1,2: 1$, then $1: 1)$ to furnish subfractions F1-F17. Fr.F10 (120 mg) was purified by pre-HPLC $\left(\mathrm{MeCN} / \mathrm{H}_{2} \mathrm{O}\right.$, v/v, from $25 / 75$ to $40 / 60$ in $20 \mathrm{~min}$, flow speed: $\left.6 \mathrm{~mL} / \mathrm{min}\right)$ to give $1\left(10.0 \mathrm{mg}, \mathrm{t}_{R}=\right.$ $10.0 \mathrm{~min})$. Fraction F6 $(50 \mathrm{mg})$ was purified by pre-HPLC $\left(\mathrm{MeCN} / \mathrm{H}_{2} \mathrm{O}\right.$, v/v, from $25 / 75$ to $45 / 55$ in $35 \mathrm{~min}$, flow speed: $3 \mathrm{~mL} / \mathrm{min})$ to afford $2\left(5.0 \mathrm{mg}, \mathrm{t}_{R}=32.5 \mathrm{~min}\right)$.

Compounds 1 and $\mathbf{2}$ were separated by chiral HPLC columns of DAICEL CORPORATION Chiralpak AD-H $(5 \mu \mathrm{m}, 4.6 \times 250 \mathrm{~mm})$. The separation chromatograms were showed in figures $\mathrm{S} 1$ and S2. 


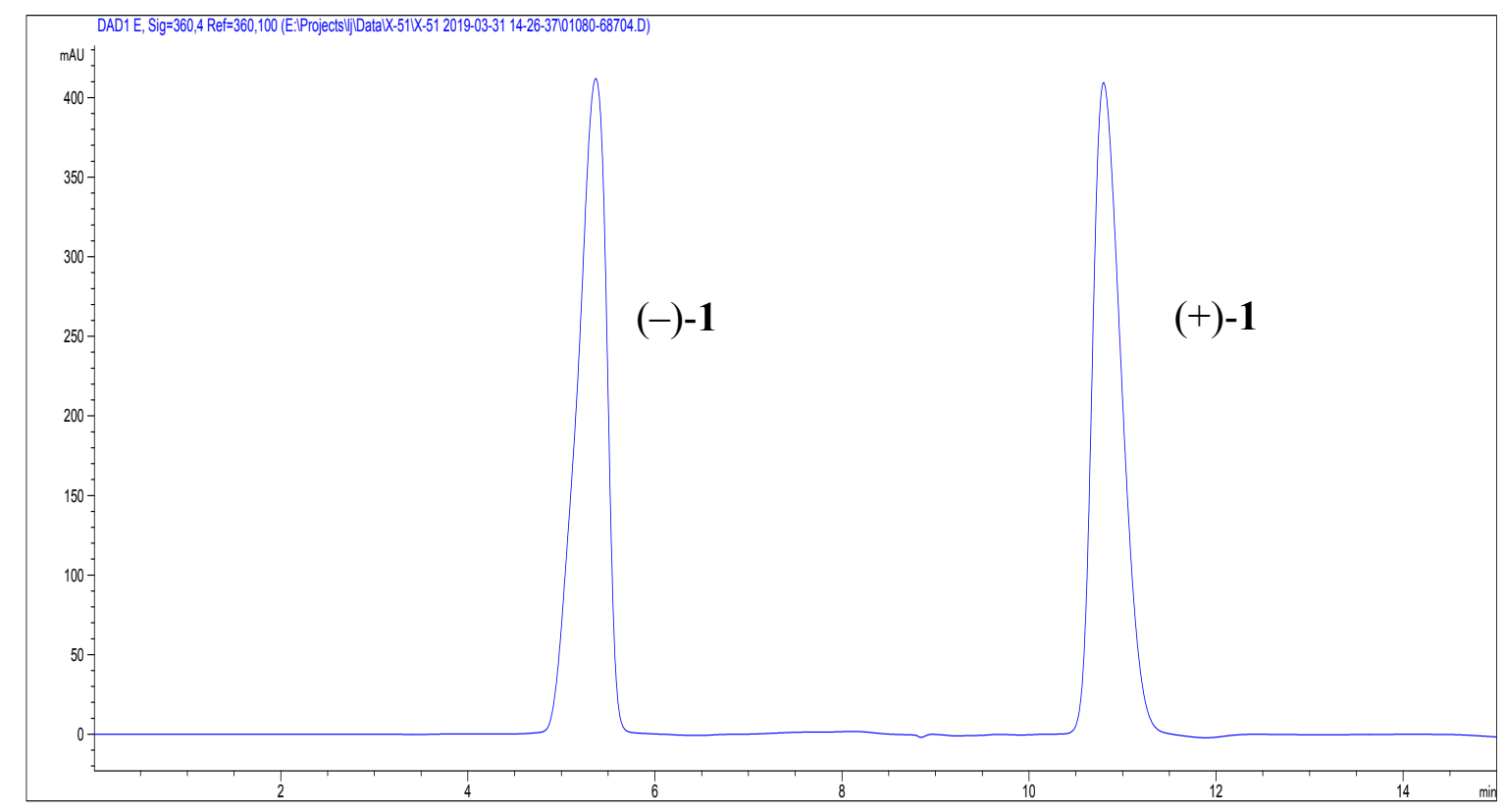

Figure S1. Chiral analysis and preparation of $( \pm)-\mathbf{1}($ CHIRALPAK AD-H, $5 \mu \mathrm{m}, 4.6 \mathrm{~mm} \times 250 \mathrm{~mm}$; Cyclohexane/Isopropanol = 98/2; flowing speed: $1 \mathrm{~mL} / \mathrm{min}$ ).

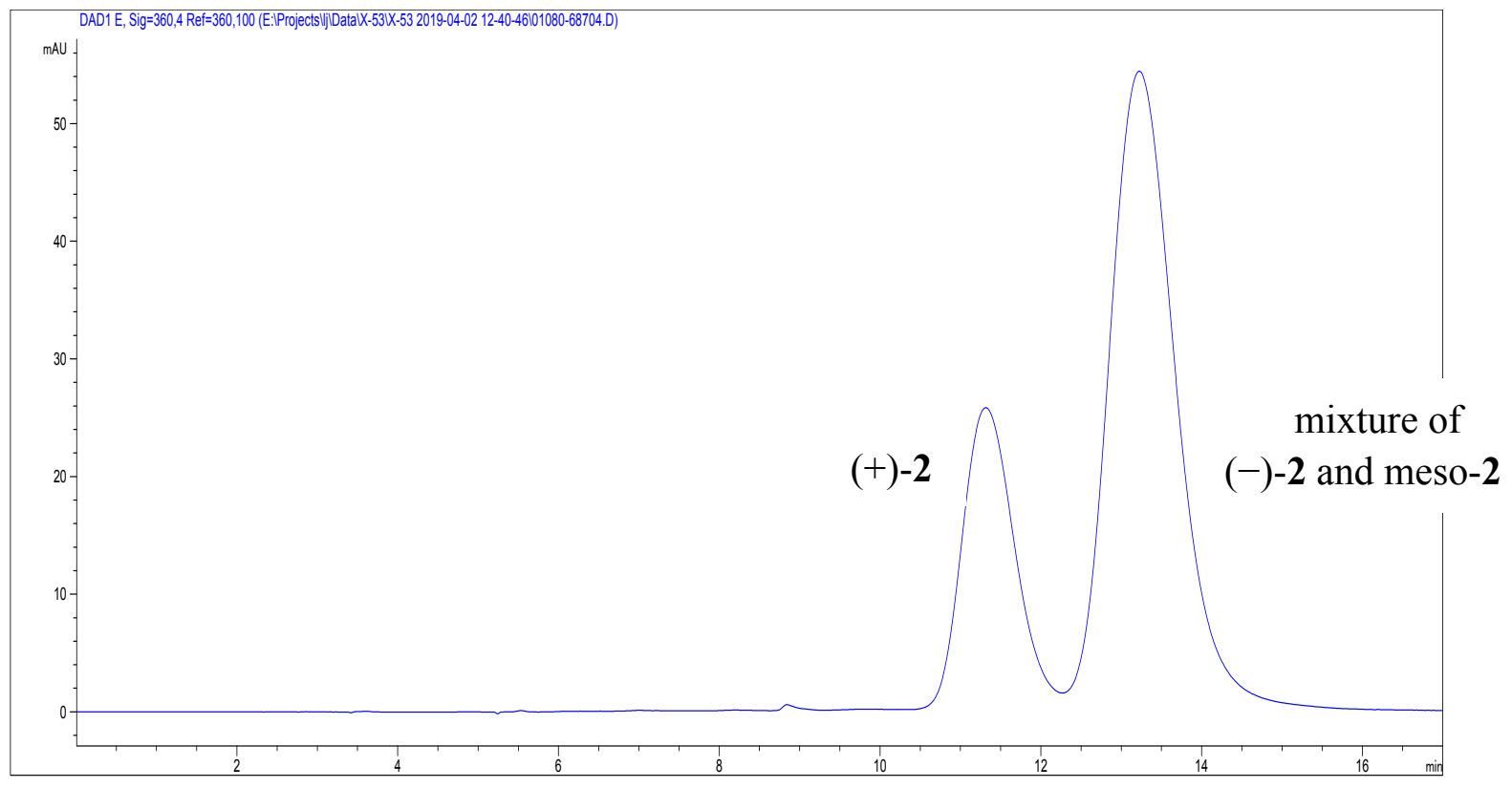

Figure S2. Chiral analysis and preparation of 2 (CHIRALPAK AD-H, $5 \mu \mathrm{m}, 4.6 \mathrm{~mm} \times 250 \mathrm{~mm}$; Cyclohexane/Isopropanol = 92/8; flowing speed: $1 \mathrm{~mL} / \mathrm{min}$ ).

Physical data for ( \pm )-xylaridine $C(\mathbf{1})$ : light yellow block-like crystals $(\mathrm{MeOH}) ; \mathrm{mp}: 68-70{ }^{\circ} \mathrm{C}$ $[(-)$-xylaridine $\mathrm{C}] ;[\alpha]^{23}{ }_{\mathrm{D}}+158.1[c 0.1, \mathrm{MeCN},(+)-1],[\alpha]^{23}{ }_{\mathrm{D}}-165.3[c 0.1, \mathrm{MeCN},(-)-1] . \mathrm{UV}$ $(\mathrm{MeOH}) \lambda_{\max } \mathrm{nm}(\log \varepsilon): 288(3.35), 348$ (3.20). IR (KBr) $v_{\max } \mathrm{cm}^{-1}: 3415,1635,1014$. For ${ }^{1} \mathrm{H}$ NMR 
$\left(600 \mathrm{MHz}, \mathrm{CDCl}_{3}\right)$ and ${ }^{13} \mathrm{C} \mathrm{NMR}\left(150 \mathrm{MHz}, \mathrm{CDCl}_{3}\right)$ spectroscopic data, see Table S1. HR-EI-MS $m / z: 333.16302[\mathrm{M}+\mathrm{H}]^{+}$(calcd for $\mathrm{C}_{18} \mathrm{H}_{24} \mathrm{~N}_{2} \mathrm{O}_{2} \mathrm{~S}, 333.16313$ ).

Crystal data for (-)-xylaridine $C(1): \mathrm{C}_{18} \mathrm{H}_{24} \mathrm{~N}_{2} \mathrm{O}_{2} \mathrm{~S} \cdot 2 \mathrm{H}_{2} \mathrm{O}, M=368.48 . a=6.7807(2) \AA, b=$ 12.6547(3) $\AA, c=22.6403(5) \AA, \alpha=90.00^{\circ}, \beta=90.00^{\circ}, \gamma=90.00^{\circ}, V=1942.71(9) \AA^{3}, T=150 \mathrm{~K}$, $\mu(\mathrm{CuK} \alpha)=0.721 \mathrm{~mm}^{-1}$. space group $=P 212121, \mathrm{Z}=4$, density $=1.260 \mathrm{~g} / \mathrm{cm}^{3}$, the final indices were $R_{1}=0.0260, w R_{2}=0.0670$. Flack parameter $=0.046(4)$. The intensity data were collected on a Bruker D8 quest diffractometer using $\mathrm{Cu} \mathrm{K \alpha}$ radiation $(\lambda=1.54178 \AA)$. The frames were integrated with the Bruker SAINT software package using a narrow-frame algorithm. Data were corrected for absorption effects using the Multi-Scan method (SADABS). The structures were solved and refined using the Bruker SHELXTL Software Package with direct methods. CCDC: 1937153 (www.ccdc.cam.ac.uk).

Physical data for xylaridine D (2) : light yellow platelet-like crystals $\left(\mathrm{CDCl}_{3} / \mathrm{MeOH}=3: 1\right)$; mp: $185-188^{\circ} \mathrm{C}$ (meso-xylaridine D); $[\alpha]^{23} \mathrm{D}+14.0[c 0.1, \mathrm{MeCN},(+)-2],[\alpha]^{23} \mathrm{D}-9.3[c 0.1, \mathrm{MeCN}$, the mixture of (-)-2/meso-2]. UV (MeOH) $\lambda_{\max } \mathrm{nm}(\log \varepsilon): 288(3.45), 355$ (3.50). IR (KBr) $v_{\max } \mathrm{cm}^{-1}$ : 3444, 1635. For ${ }^{1} \mathrm{H} \mathrm{NMR}\left(600 \mathrm{MHz}, \mathrm{CDCl}_{3}\right)$ and ${ }^{13} \mathrm{C} \mathrm{NMR}\left(150 \mathrm{MHz}, \mathrm{CDCl}_{3}\right)$ spectroscopic data, see Table S2. HR-EI-MS m/z: $663.30298[\mathrm{M}+\mathrm{H}]^{+}\left(\right.$calcd for $\mathrm{C}_{36} \mathrm{H}_{46} \mathrm{~N}_{4} \mathrm{O}_{4} \mathrm{~S}_{2}, 663.30332$ ).

Crystal data for meso-xylaridine $D$ (2): $\mathrm{C}_{36} \mathrm{H}_{46} \mathrm{~N}_{4} \mathrm{O}_{4} \mathrm{~S}_{2}, M=662.89 . a=12.0587(4) \AA, b=$ 16.4831(6) $\AA, c=8.5192(3) \AA, \alpha=90^{\circ}, \beta=96.2480(10)^{\circ}, \gamma=90^{\circ}, V=1683.26(10) \AA^{3}, T=150 \mathrm{~K}$, $\mu(\mathrm{CuK} \alpha)=0.721 \mathrm{~mm}^{-1}$. space group $=P 21 / \mathrm{c}, \mathrm{Z}=2$, density $=1.308 \mathrm{~g} / \mathrm{cm}^{3}$, the final indices were $R_{1}$ $=0.09268, w R_{2}=0.1888$. The intensity data were collected on a Bruker D8 quest diffractometer using $\mathrm{Cu} \mathrm{K \alpha}$ radiation $(\lambda=1.54178 \AA)$. The frames were integrated with the Bruker SAINT software package using a narrow-frame algorithm. Data were corrected for absorption effects using the 
Multi-Scan method (SADABS). The structures were solved and refined using the Bruker SHELXTL

Software Package with direct methods. CCDC: 1937157 (www.ccdc.cam.ac.uk).

Table S1. ${ }^{1} \mathrm{H}(600 \mathrm{MHz})$ and ${ }^{13} \mathrm{C}(150 \mathrm{MHz}) \mathrm{NMR}$ data of compound 1 in $\mathrm{CDCl}_{3}$.

\begin{tabular}{|c|c|c|c|c|c|}
\hline No. & $\delta_{\mathrm{H}}$ & $\delta_{\mathrm{C}}$ & No. & $\delta_{\mathrm{H}}$ & $\delta_{\mathrm{C}}$ \\
\hline 2 & \multirow{9}{*}{$2.78(\mathrm{~s})$} & 66.2 & 11 & & 196.9 \\
\hline 3 & & 202.2 & 12 & & 57.7 \\
\hline 4 & & 131.3 & 14 & $1.39(\mathrm{~s})$ & $26.9^{\mathrm{a}}$ \\
\hline 5 & & 136.3 & 15 & $1.40(\mathrm{~s})$ & $27.8^{\mathrm{a}}$ \\
\hline 6 & & 152.8 & 16 & $2.03(\mathrm{~s})$ & 11.6 \\
\hline 7 & & 49.8 & 17 & $1.96(\mathrm{~s})$ & 12.4 \\
\hline 8 & & 53.4 & 18 & $1.40(\mathrm{~s})$ & $28.1^{\mathrm{b}}$ \\
\hline 9 & & 154.6 & 19 & $1.32(\mathrm{~s})$ & $28.8^{\mathrm{b}}$ \\
\hline 10 & & 125.4 & 20 & $1.44(\mathrm{~s})$ & 26.3 \\
\hline \multicolumn{6}{|c|}{${ }^{\mathrm{a} D a t a}$ are interchangable. ${ }^{\mathrm{b}}$ Data are interchangable. } \\
\hline
\end{tabular}

Table S2. ${ }^{1} \mathrm{H}(600 \mathrm{MHz})$ and ${ }^{13} \mathrm{C}(150 \mathrm{MHz}) \mathrm{NMR}$ data of compound 2 in $\mathrm{CDCl}_{3}$.

\begin{tabular}{|c|c|c|c|c|}
\hline \multirow{2}{*}{ No. ${ }^{c}$} & \multicolumn{2}{|c|}{$( \pm)-2$} & \multicolumn{2}{|c|}{ meso-2 $^{\mathrm{d}}$} \\
\hline & $\overline{\delta_{\mathrm{H}}}$ & $\delta_{\mathrm{C}}$ & $\delta_{\mathrm{H}}$ & $\delta_{\mathrm{C}}$ \\
\hline $2 / 2^{\prime}$ & & 66.3 & & 66.3 \\
\hline $3 / 3^{\prime}$ & & 201.9 & & 201.8 \\
\hline $4 / 4^{\prime}$ & & 133.8 & & 133.9 \\
\hline $5 / 5^{\prime}$ & & 136.8 & & 136.9 \\
\hline $6 / 6^{\prime}$ & & 152.9 & & 152.8 \\
\hline $7 / 7^{\prime}$ & $2.78(\mathrm{~m})$ & 49.9 & $2.78(\mathrm{~m})$ & 50.0 \\
\hline $8 / 8^{\prime}$ & & 53.4 & & 53.3 \\
\hline 9/9' & & 154.5 & & 154.3 \\
\hline $10 / 10^{\prime}$ & & 125.5 & & 125.4 \\
\hline $11 / 11^{\prime}$ & & 196.9 & & 196.8 \\
\hline $12 / 12^{\prime}$ & & 57.8 & & 57.7 \\
\hline $14 / 14^{\prime}$ & $1.37(\mathrm{~s})$ & $27.0^{\mathrm{a}}$ & $1.37(\mathrm{~s})$ & $27.2^{\mathrm{a}}$ \\
\hline $15 / 15^{\prime}$ & $1.38(\mathrm{~s})$ & $27.9^{\mathrm{a}}$ & $1.38(\mathrm{~s})$ & $27.8^{\mathrm{a}}$ \\
\hline $16 / 16^{\prime}$ & $2.77(\mathrm{~m})$ & 23.4 & $2.73,2.89(\mathrm{~m})$ & 23.7 \\
\hline $17 / 17^{\prime}$ & $1.96(\mathrm{~s})$ & 12.6 & $1.95(\mathrm{~s})$ & 12.6 \\
\hline $18 / 18^{\prime}$ & $1.42(\mathrm{~s})$ & $28.1^{\mathrm{b}}$ & $1.40(\mathrm{~s})$ & $28.2^{\mathrm{b}}$ \\
\hline 19/19' & $1.33(\mathrm{~s})$ & $28.9^{\mathrm{b}}$ & $1.33(\mathrm{~s})$ & $28.8^{\mathrm{b}}$ \\
\hline $20 / 20^{\prime}$ & $1.46(\mathrm{~s})$ & 26.4 & $1.44(\mathrm{~s})$ & 26.3 \\
\hline \multicolumn{5}{|c|}{$\begin{array}{l}\text { Data are interchangable. }{ }^{b} \text { Data are interchangable. }{ }^{c}( \pm)-2 \text { and } \\
\text { meso- } 2 \text { have rotational and reflectional symmetry, respectively, } \\
\text { Therefore, the chemical shifts of symmetric carbons are exactly } \\
\text { the same. }{ }^{d} \text { Data were assigned by HSQC and HMBC } \\
\text { correlations. }\end{array}$} \\
\hline
\end{tabular}

1.4. ECD calculations of 1 and 2. The conformers of compounds 1 and 2 was generated by Confab with $50 \mathrm{kcal} / \mathrm{mol}$ cutoff energy. ${ }^{1}$ Gaussian09 software package was used to perform DFT calculations. $^{2}$ The optimization and frequency calculation of conformers were performed on B3PW91-D3/6-31G(d) level of theory with IEF-PCM solvent model (MeOH). Theoretical ECD 
(TDDFT) of compounds 1 and $\mathbf{2}$ was calculated on mPW1PW91/6-311G(d) level with IEF-PCM solvent model $(\mathrm{MeOH})$ as well. SpecDis v1.71 was used to simulate the ECD curve with sigma/gamma value $0.35 \mathrm{eV}^{3}$ The calculated ECD curve of each conformer was Boltzmann averaged based on their Gibbs free energy. The averaged calculated ECD curve of 2 was adjusted by blue shifting for $10 \mathrm{~nm}$.

\section{References}

S1. N. M. O’Boyle, T. Vandermeersch, C. J. Flynn, A. R. Maguire, G. R. Hutchison, J. Cheminform. 2011, 3, 8 .

S2. Gaussian 09, Revision A.02, M. J. Frisch, G. W. Trucks, H. B. Schlegel, G. E. Scuseria, M. A. Robb, J. R. Cheeseman, G. Scalmani, V. Barone, G. A. Petersson, H. Nakatsuji, X. Li, M. Caricato, A. Marenich, J. Bloino, B. G. Janesko, R. Gomperts, B. Mennucci, H. P. Hratchian, J. V. Ortiz, A. F. Izmaylov, J. L. Sonnenberg, D. Williams-Young, F. Ding, F. Lipparini, F. Egidi, J. Goings, B. Peng, A. Petrone, T. Henderson, D. Ranasinghe, V. G. Zakrzewski, J. Gao, N. Rega, G. Zheng, W. Liang, M. Hada, M. Ehara, K. Toyota, R. Fukuda, J. Hasegawa, M. Ishida, T. Nakajima, Y. Honda, O. Kitao, H. Nakai, T. Vreven, K. Throssell, J. A. Montgomery, Jr., J. E. Peralta, F. Ogliaro, M. Bearpark, J. J. Heyd, E. Brothers, K. N. Kudin, V. N. Staroverov, T. Keith, R. Kobayashi, J. Normand, K. Raghavachari, A. Rendell, J. C. Burant, S. S. Iyengar, J. Tomasi, M. Cossi, J. M. Millam, M. Klene, C. Adamo, R. Cammi, J. W. Ochterski, R. L. Martin, K. Morokuma, O. Farkas, J. B. Foresman, and D. J. Fox, Gaussian, Inc., Wallingford CT, 2016.

S3. Bruhn, T.; Schaumlöffel, A.; Hemberger, Y.; Bringmann, G. Chirality 2013, 25, 243-249.

1.5. Antibacterial assay. Compounds were first tested for their potential against four bacterial 
strains at the single concentration of 128 or $50 \mathrm{mg} / \mathrm{mL}(\mathrm{n}=2)$. The tested bacteria strains Escherichia coli ATCC25922, Staphylococcus aureus subsp. aureus ATCC29213, Salmonella enterica subsp. enterica ATCC14028, Pseudomonas aeruginosa ATCC27853 were purchased from China General Microbiological Culture Collection Center, (CGMCC). All these strains were cultured in Mueller Hinton broth (MHB) (Guangdong Huankai Microbial Sci. \&Tech. Co., Ltd.) at $37{ }^{\circ} \mathrm{C}$ overnight with shaking $(200 \mathrm{rpm})$. A sample of each culture was then diluted 40-fold in fresh MHB broth and incubated with shaking $(200 \mathrm{rpm})$ at $37{ }^{\circ} \mathrm{C}$ for $2-3 \mathrm{~h}$. The resultant mid-log phase cultures were diluted to a concentration of $5 \times 10^{5} \mathrm{CFU} / \mathrm{mL}$, then $50 \mathrm{~mL}$ was added to each well of the compound-containing plates, giving a final compound concentration range of 128 or $50 \mathrm{mg} / \mathrm{mL}$. Plates were covered and incubated at $37^{\circ} \mathrm{C}$ for $24 \mathrm{~h}$. Inhibition rate were determined using photometry at $\mathrm{OD}_{625 \mathrm{~nm}}$. Penicillin G sodium salt (Biosharp), ceftazidime (Shanghai Yuanye Biotechnologies) were used as positive inhibitor controls.

1.6. Cytotoxicity assay. Cytotoxicity was tested with Cell Counting Kit-8 (CCK-8) assay. Briefly, fresh spleen cells were gained from female BALB/c mice $(18-20 \mathrm{~g})$. Spleen cells $\left(1 \times 10^{6}\right.$ cells $)$ were seeded in triplicate in 96 -well flat plates and cultured at $37^{\circ} \mathrm{C}$ for $48 \mathrm{~h}$ in 96 -well flat plates, in the presence or absence of various concentrations of compounds, in a humidified and 5\% $\mathrm{CO}_{2}$-containing incubator. A certain amount of CCK-8 was added to each well at the final 8-10 $\mathrm{h}$ of culture. To the end of the culture, we measured the OD values with microplate reader (Bio Rad 650) at $450 \mathrm{~nm}$. Cyclosporin A (CsA) an immunosuppressive agent, was used as positive compound with definite activity, and the OD values from medium only culture were used as background. The cytotoxicity of each compound was expressed as the concentration of compound that reduced cell viability to $50 \%\left(\mathrm{CC}_{50}\right)$. 
2. NMR spectra, HRESIMS and CD spectra of xylaridine C (1) and xylaridine D (2)

2.1 NMR spectra, HRESIMS and CD spectra of xylaridine C (1)<smiles>[CH]1C=C[CH-]1</smiles>

${ }^{1} \mathrm{H} N M R$
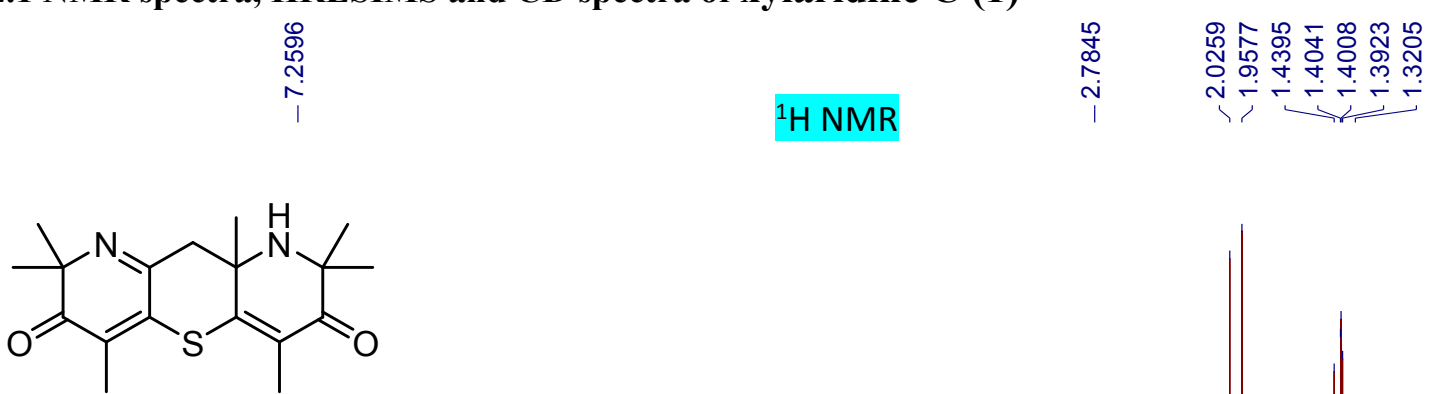

$( \pm)$-Xylariadine C (1)
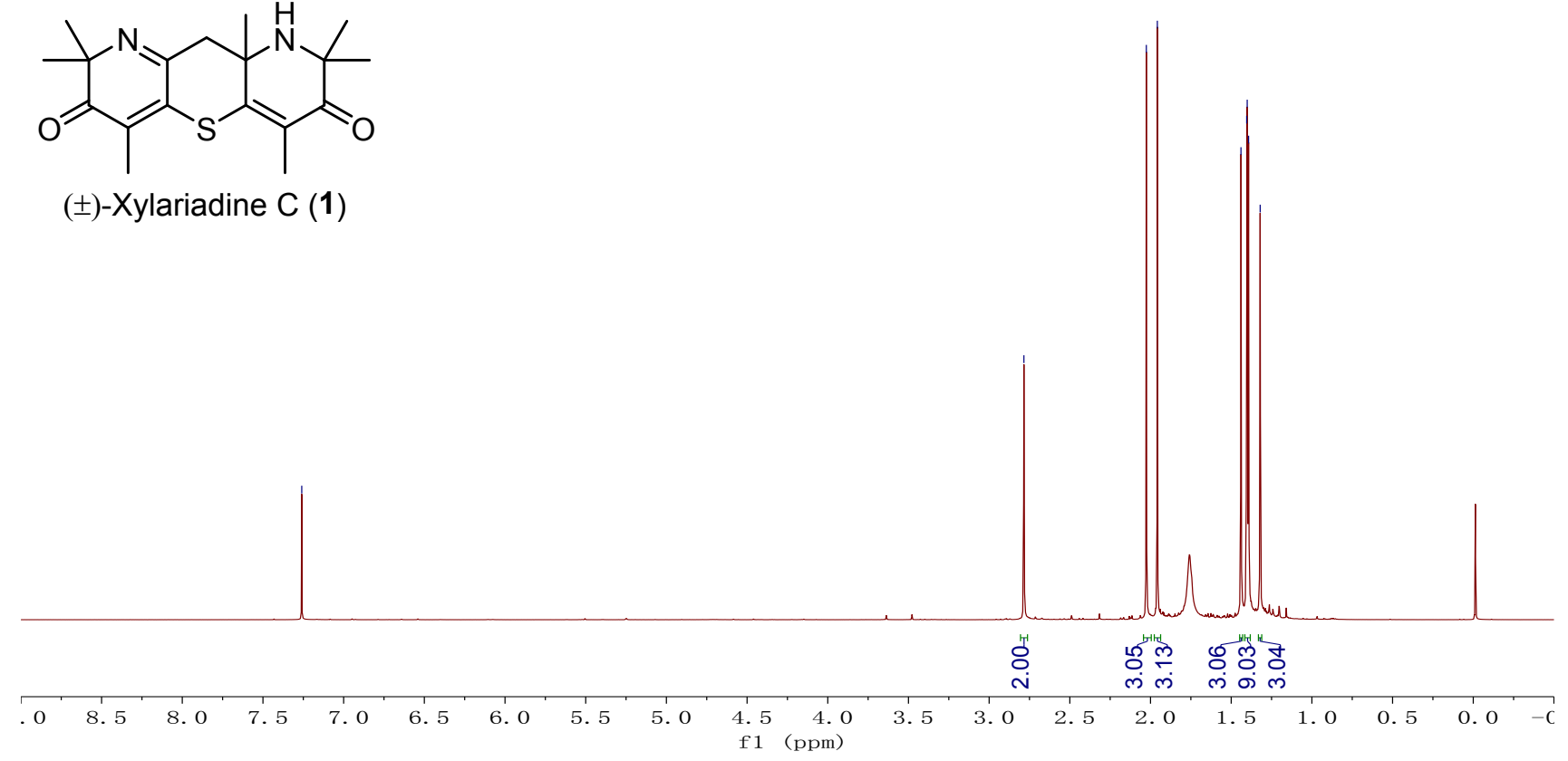

\section{${ }^{13} \mathrm{C} N M R$}

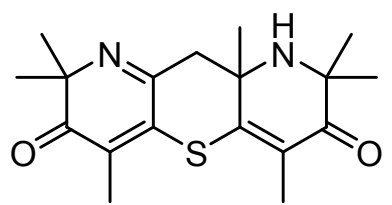

( \pm )-Xylariadine C (1)

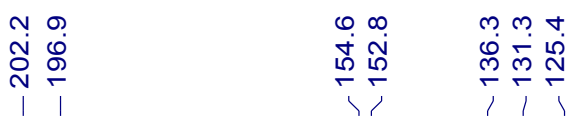

ध่

,

vit

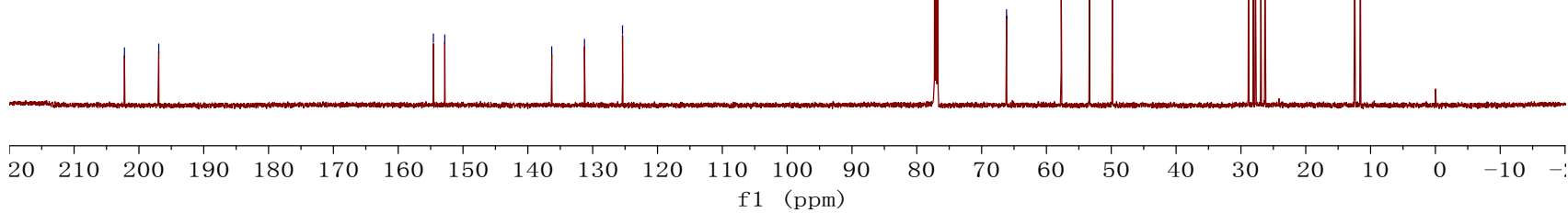




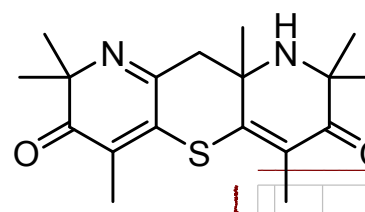

$( \pm)$-Xylariadine C (1)
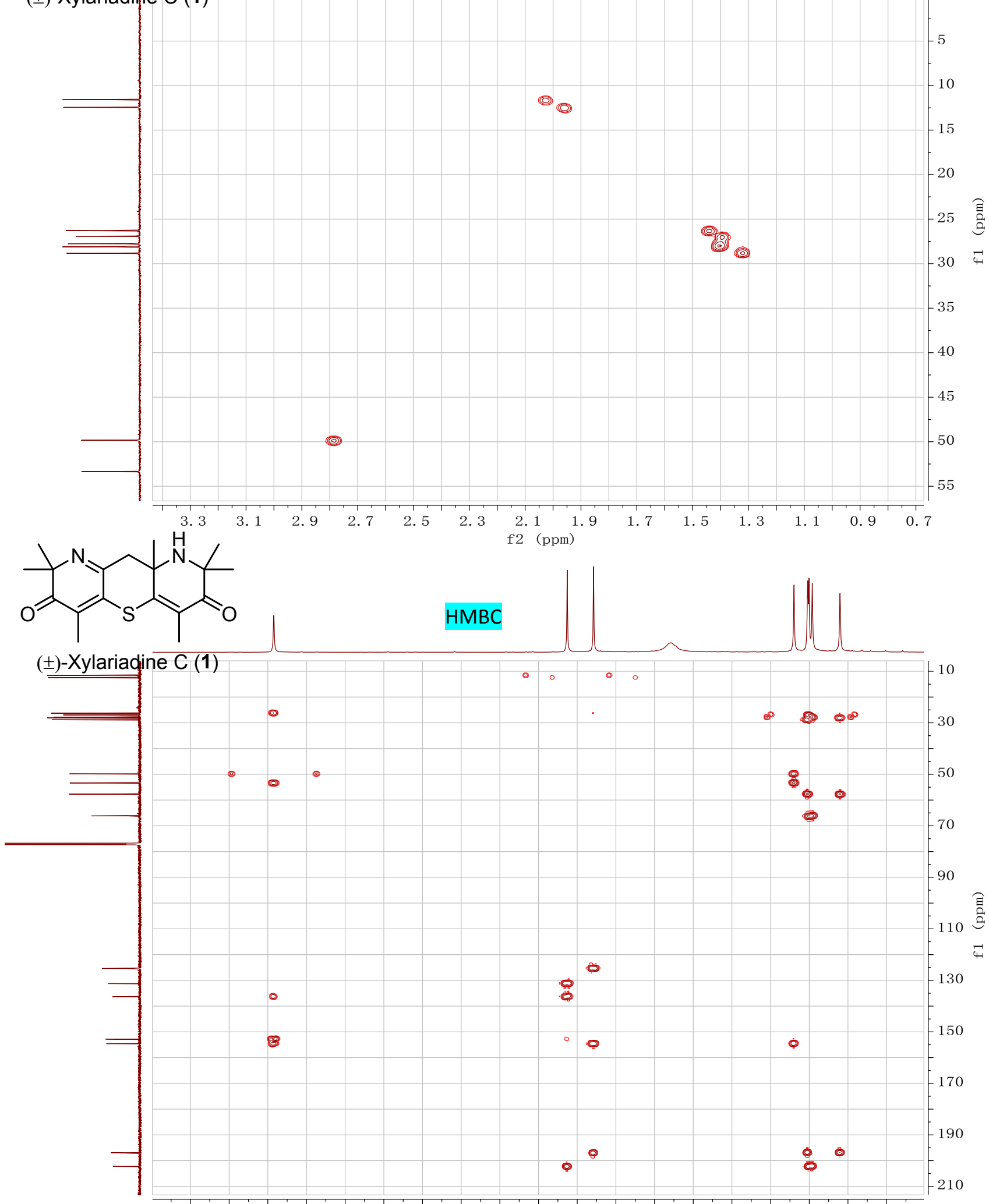

HSQC $\underbrace{\underbrace{H} \|}$

$\begin{array}{llllllllllllllllllllll}3.0 & 2.9 & 2.8 & 2.7 & 2.6 & 2.5 & 2.4 & 2.3 & 2.2 & 2.1 & 2.0 & 1.9 & 1.8 & 1.7 & 1.6 & 1.5 & 1.4 & 1.3 & 1.2\end{array}$ f2 (ppm) 

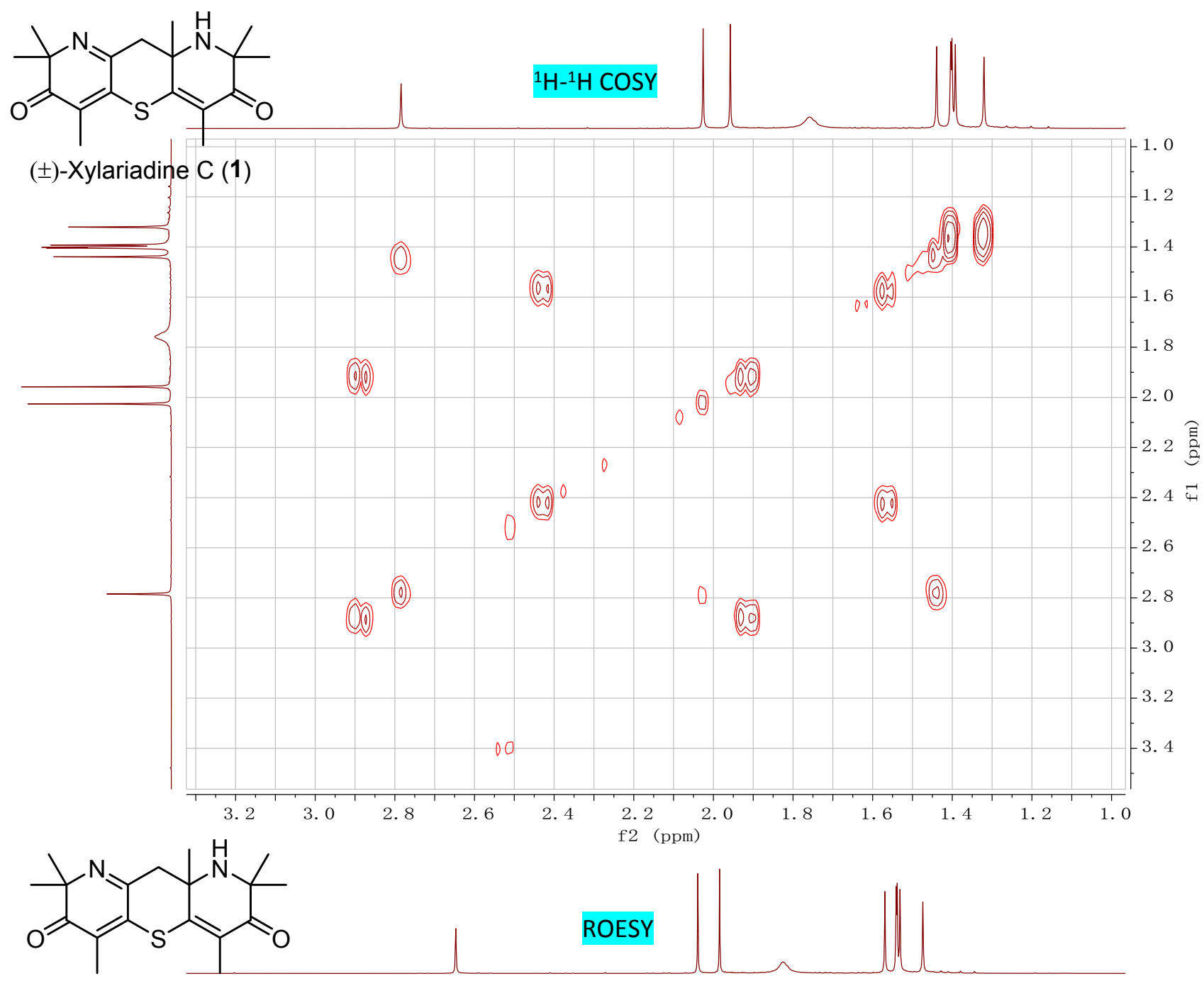

( \pm )-Xylariadine C (1)

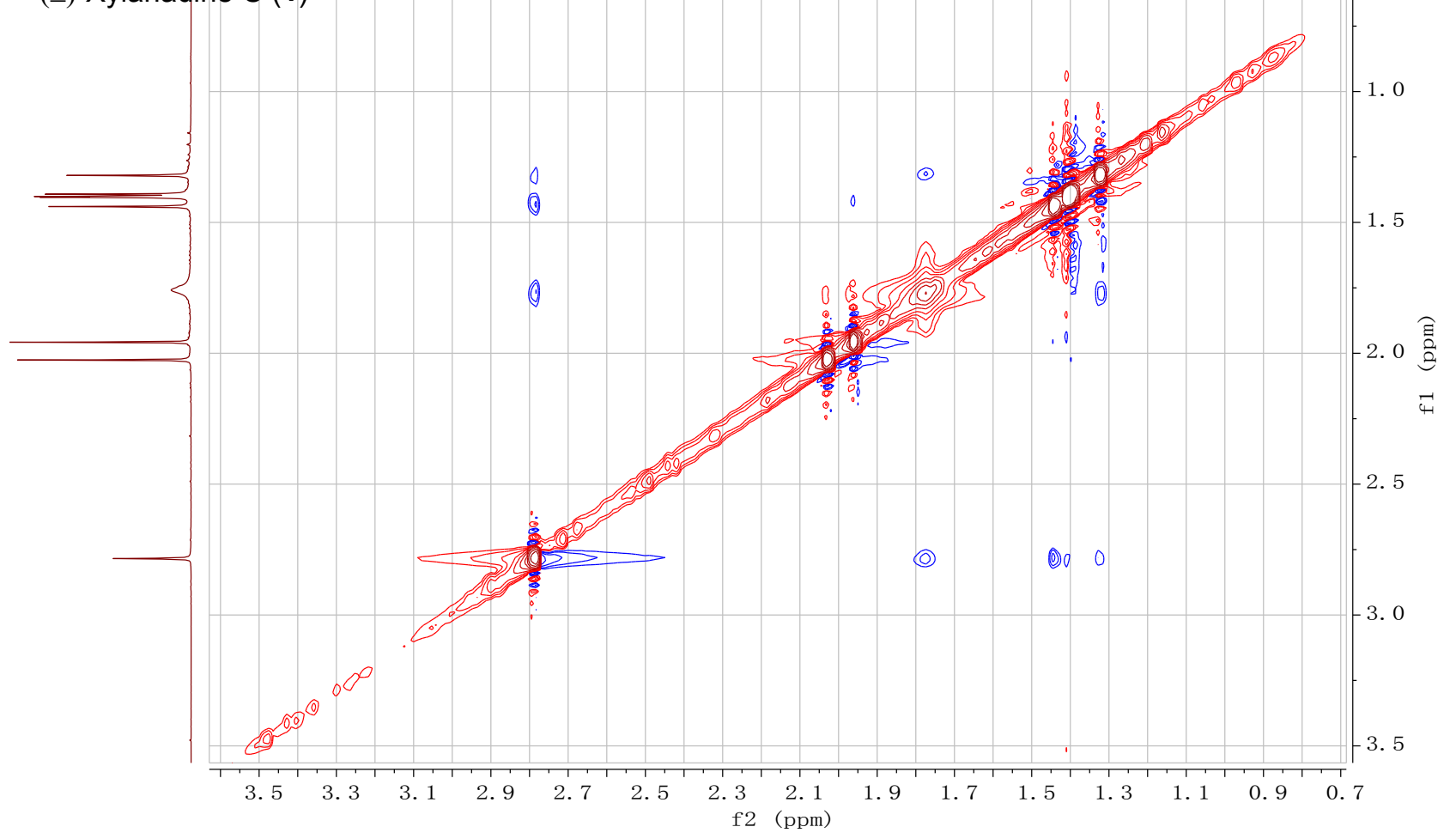




\section{HRESIMS}

D:LIJINGL201803220180318X-51

03/18:18 20:45:17

X-51 \#997 RT: 13.78 AV: 1 NL: $1.46 E 9$

T: FTMS + p ESI Full lock ms [100.0000-1000.0000]

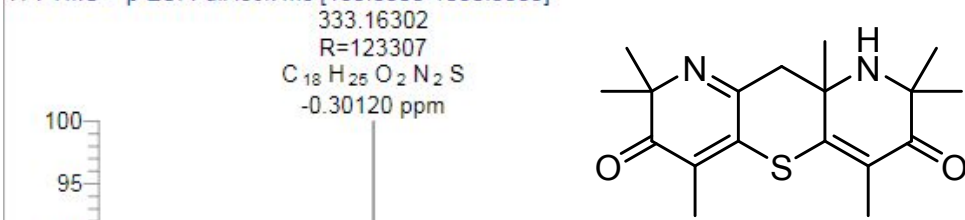

$( \pm)$-Xylariadine C (1)

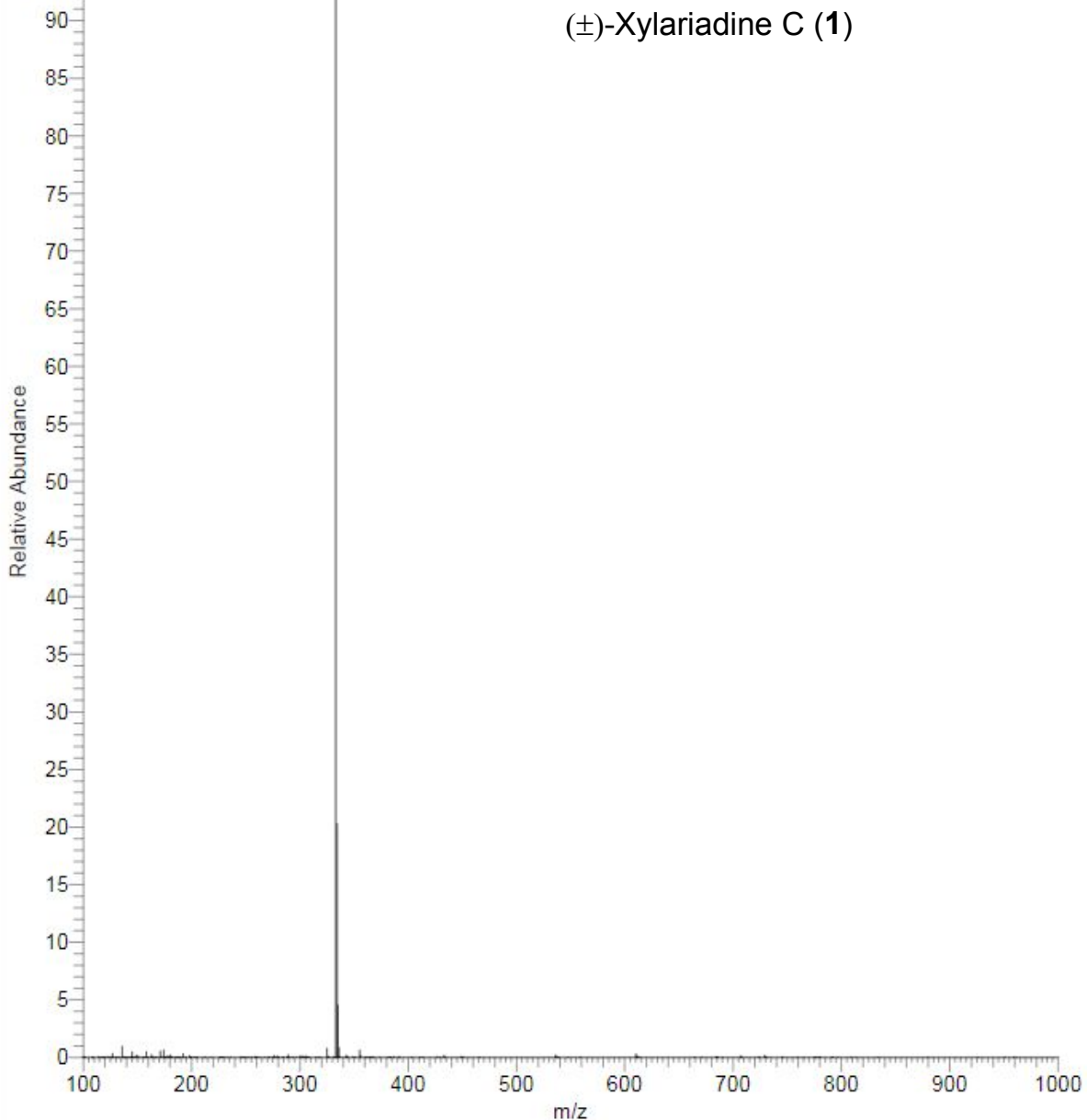



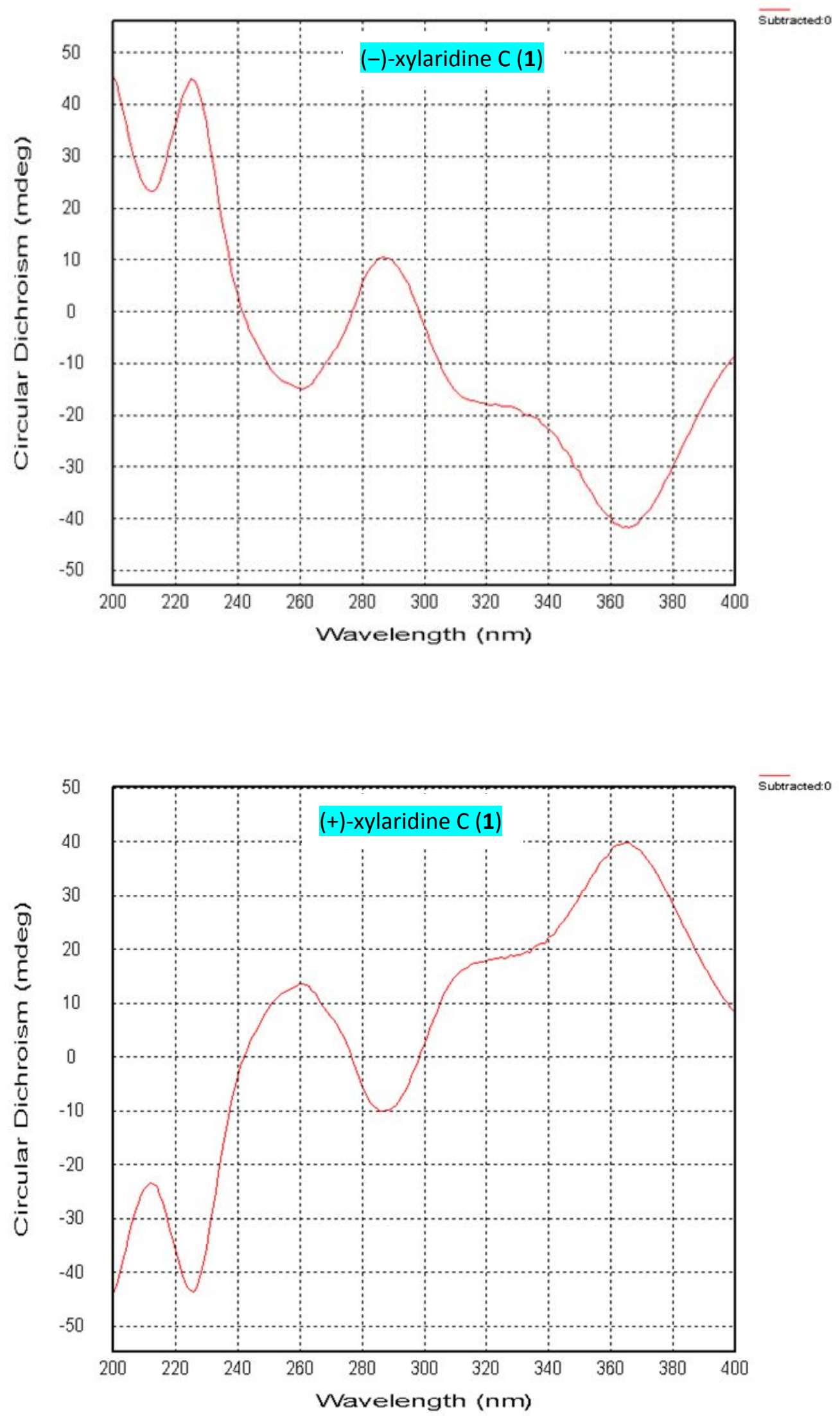

$\overline{\text { Subtracted:0 }}$ 


\subsection{NMR spectra and HRESIMS of xylaridine D (2)}

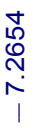

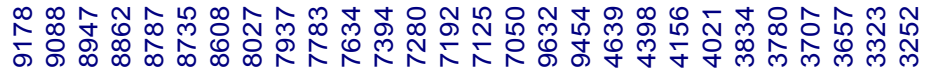
๙

\section{${ }^{1} \mathrm{H} N M R$}
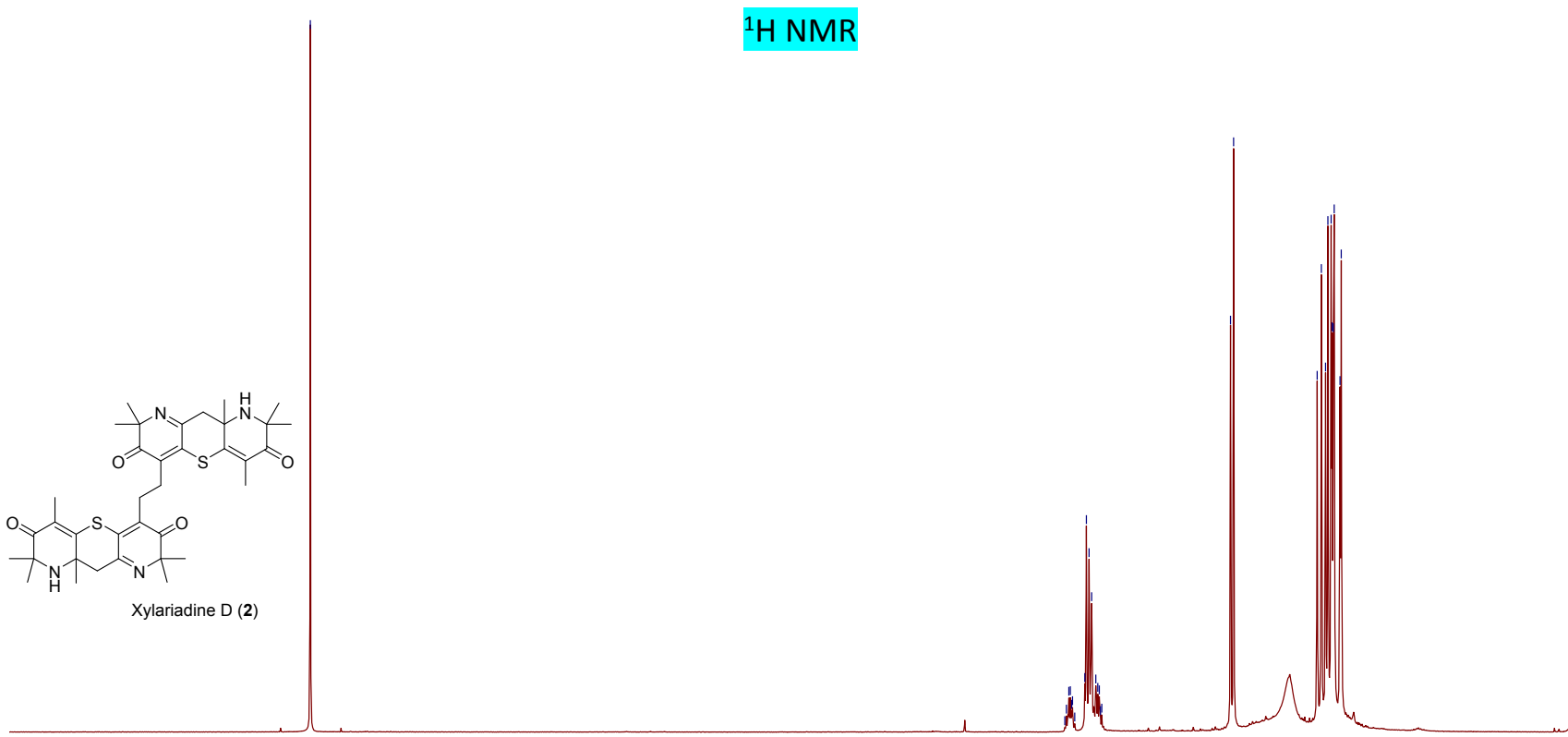

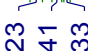

औo

(1)

\begin{tabular}{lllllllllllllllllll}
\hline 0 & 8.5 & 8.0 & 7.5 & 7.0 & 6.5 & 6.0 & 5.5 & 5.0 & 4.5 & 4.0 & 3.5 & 3.0 & 2.5 & 2.0 & 1.5 & 1.0 & 0.5 & 0
\end{tabular}

\section{${ }^{13} \mathrm{C}$ NMR}

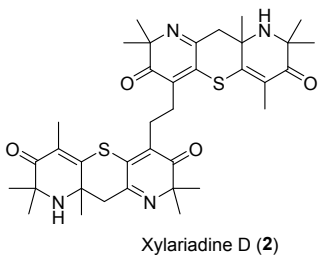

$の \infty の \infty$

ธ่

Y
เ 它 $\rightarrow$ isis $m m \infty n+m o b a \infty n-\infty m n o t m n+00$

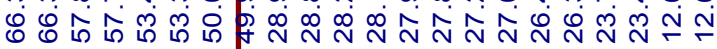

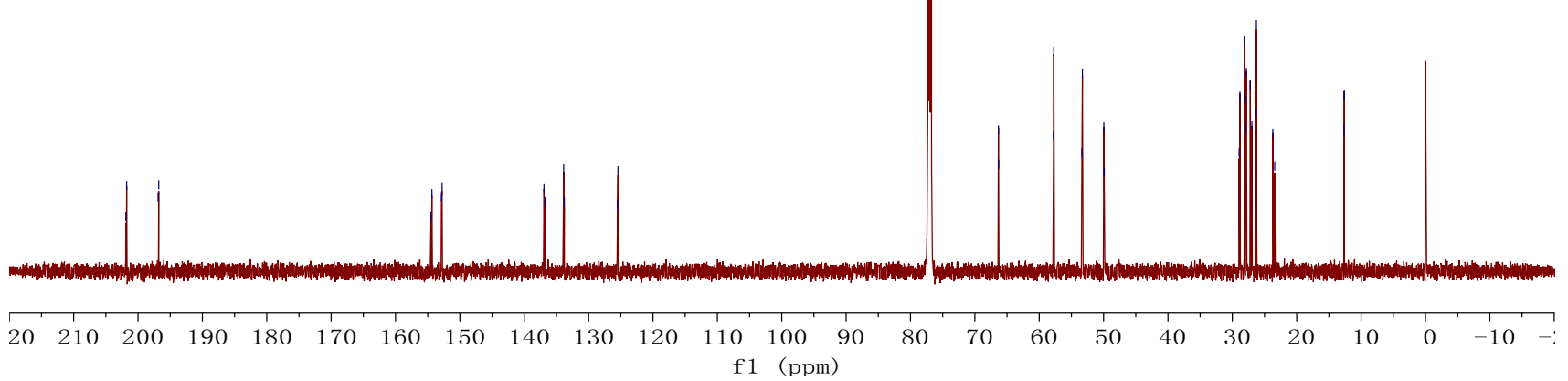




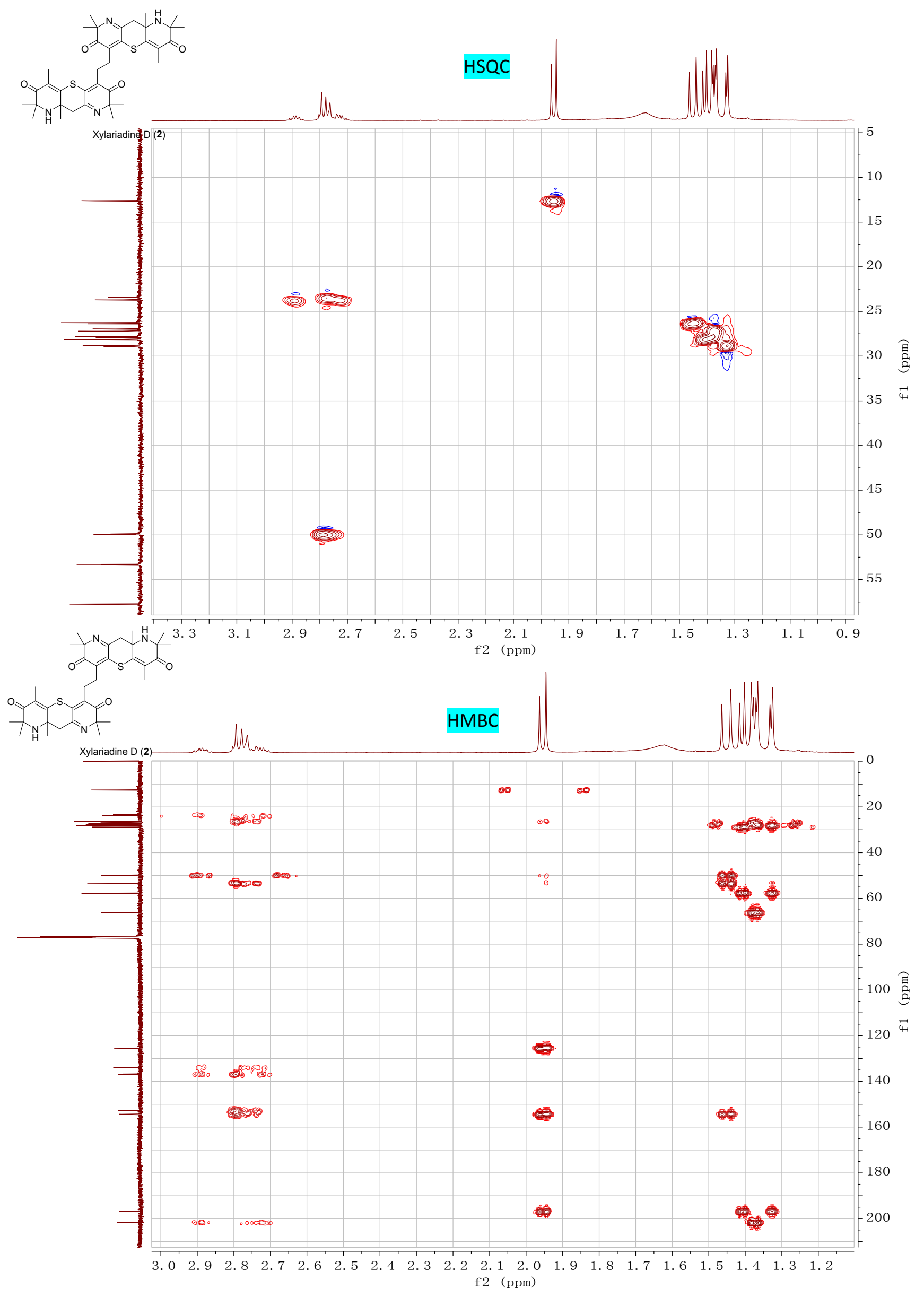




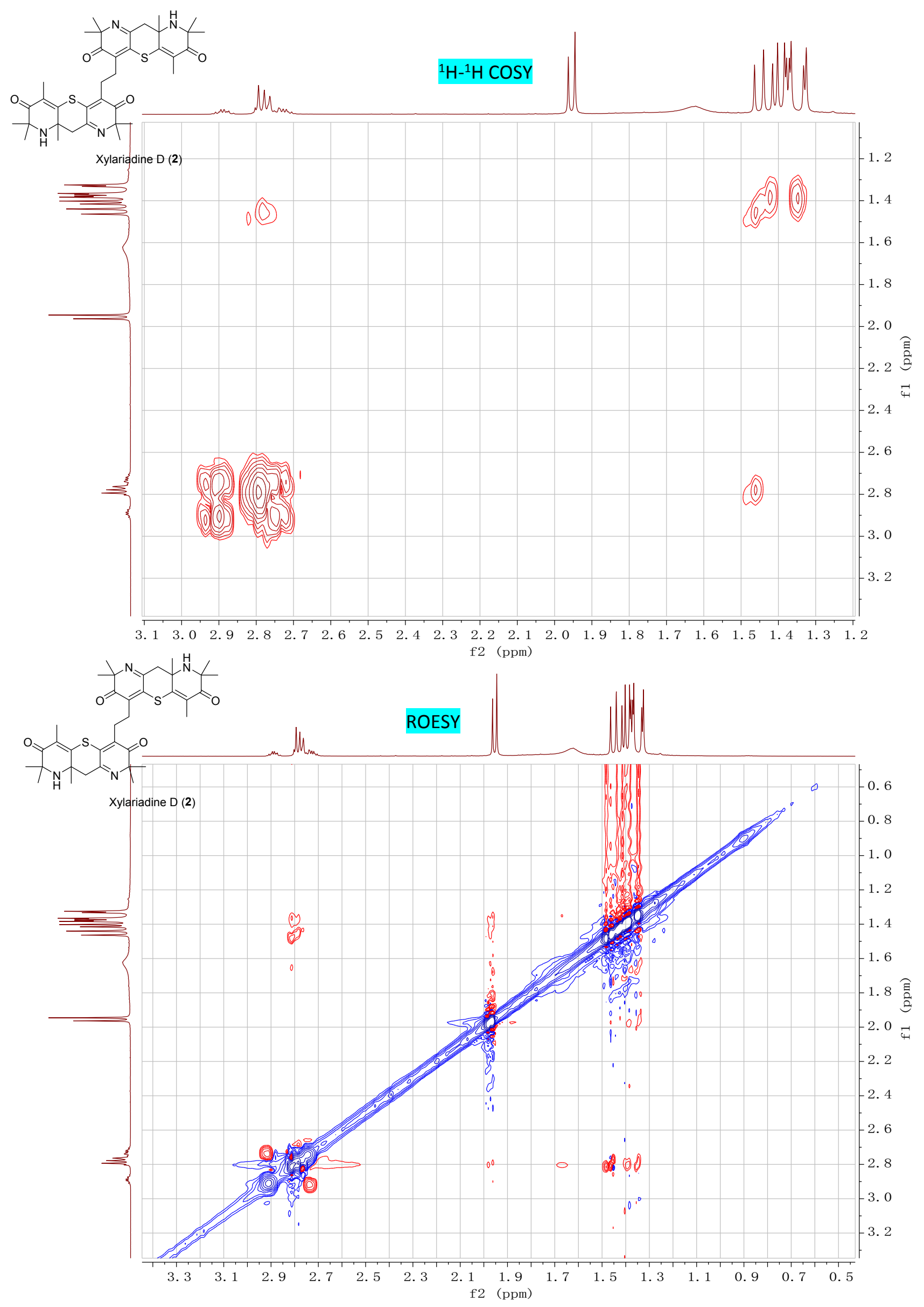


|D:11-Liu-jikail... |201903120190326U-53

X-53\#1837 RT: 16.02 AV: 1 NL: $1.39 E 8$

T: FTMS + p ESI Full lock ms [250.0000-2000.0000] 332.15540

$\mathrm{C}_{18} \mathrm{H}_{24} \mathrm{O}_{2} \mathrm{~N}_{2} \mathrm{~S}$

$100 \quad 0.09529 \mathrm{mmu}$

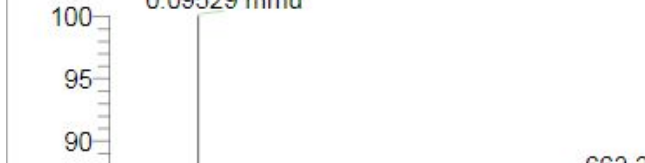

\section{HRESIMS}

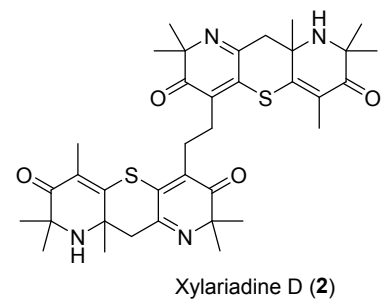

663.30310

$\mathrm{C}_{36} \mathrm{H}_{47} \mathrm{O}_{4} \mathrm{~N}_{4} \mathrm{~S}_{2}$

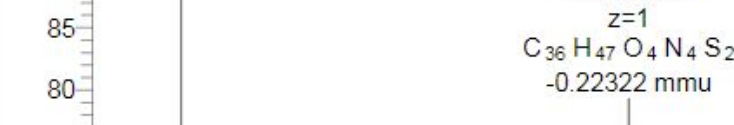

5

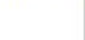


2.3. ${ }^{1} \mathrm{H}$ NMR spectra for the mixture of (-)-2 and meso-2

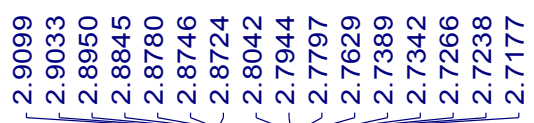

(-)-2 and meso-2

in a ratio of 1:2

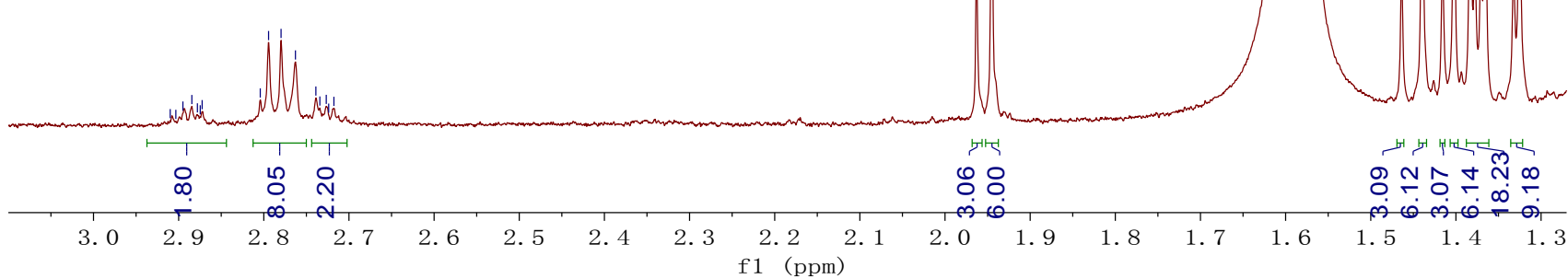


2.4. ${ }^{1} \mathrm{H}$ NMR spectra for (+)-2, the mixture of (-)-2 and meso-2, and 2

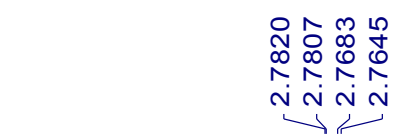

(+)-xylaridine D (2)

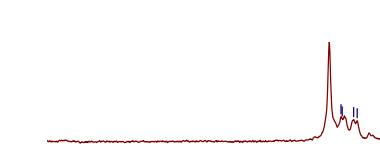

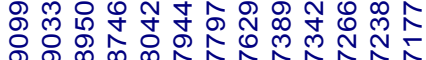

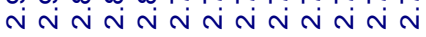

The mixture of

(-)-2 and meso-2

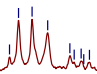

$\infty$
$\infty$
$\infty$
0

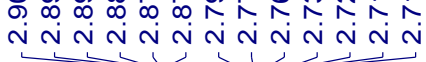

\section{xylaridine D (2)}

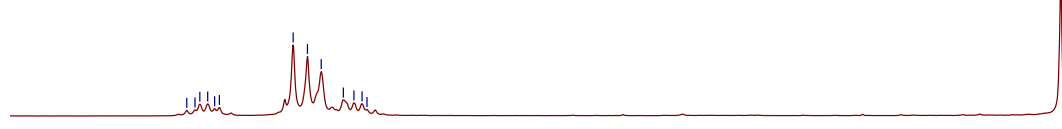

范

요 in

हैं

\&

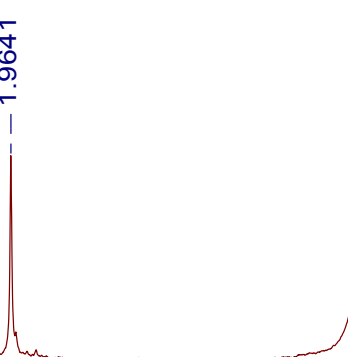

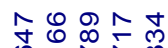

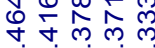

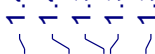

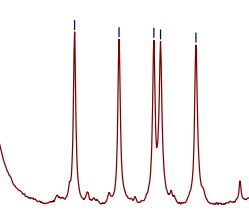

$\infty$ 舟

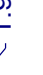

广

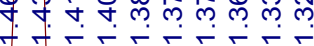

$\begin{array}{lllll}3.0 & 2.9 & 2.8 & 2.7 & 2.6\end{array}$ f1 (ppm)

3. The ECD calculation data of xylaridine C (1) and xylaridine D (2)

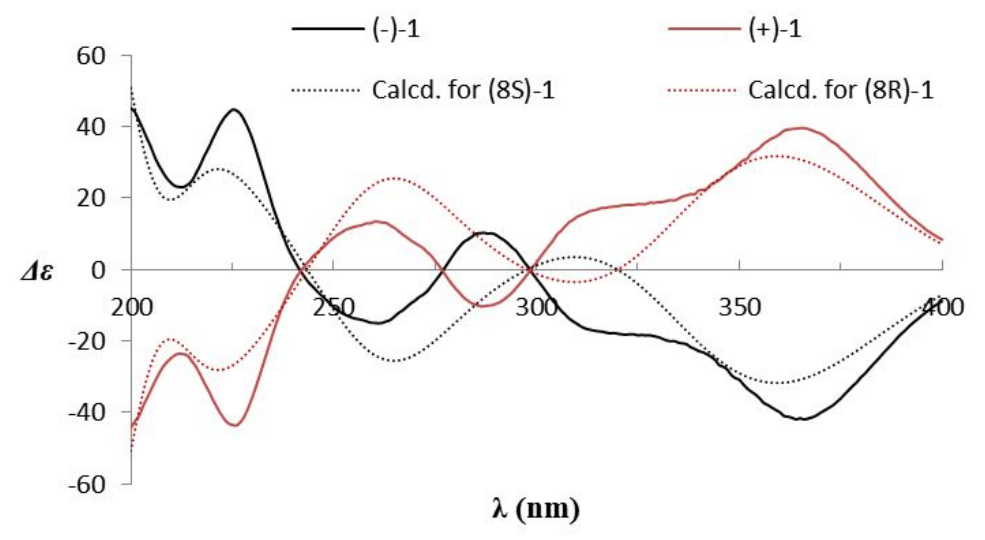

Figure S3. Experimental and calculated ECD spectra of $\mathbf{1}$.

The coordinates of compound (-)-1

$\begin{array}{llrl}\mathrm{S} & 7.5790323075 & 6.3354476245 & 9.4309790836 \\ \mathrm{O} & 11.5973422276 & 9.0233806147 & 10.7987602006 \\ \mathrm{~N} & 8.4461454166 & 10.2601444609 & 9.4187301007\end{array}$




$\begin{array}{llcc}\mathrm{C} & 9.8122516775 & 10.3265021524 & 9.904081491 \\ \mathrm{O} & 3.1468742614 & 5.1636855599 & 7.4070187489 \\ \mathrm{C} & 10.657462989 & 10.9074817488 & 8.75625502 \\ \mathrm{~N} & 4.7545111756 & 8.3201220251 & 7.3246689366 \\ \mathrm{C} & 6.1216715958 & 8.0626957012 & 7.7589067154 \\ \mathrm{C} & 10.4683427645 & 9.0146306428 & 10.3268345633 \\ \mathrm{C} & 9.732989374 & 7.7626642221 & 10.1188334292 \\ \mathrm{C} & 8.468342037 & 7.8448188159 & 9.6244311857 \\ \mathrm{C} & 7.8433282805 & 9.1430487693 & 9.304645922 \\ \mathrm{C} & 6.4248587761 & 9.14471138 & 8.8179088355 \\ \mathrm{C} & 3.9738529051 & 7.2731939767 & 6.6656146038 \\ \mathrm{C} & 9.8165399964 & 11.2815210186 & 11.106624606 \\ \mathrm{C} & 6.1654121843 & 6.7262190253 & 8.4536537994 \\ \mathrm{C} & 5.1898381023 & 5.7893033043 & 8.3912163759 \\ \mathrm{C} & 4.0252119603 & 6.0054822548 & 7.5126857339 \\ \mathrm{C} & 4.4437723802 & 6.8722307329 & 5.2496212227 \\ \mathrm{C} & 5.2519456629 & 4.4919126328 & 9.1435742491 \\ \mathrm{C} & 10.4051636338 & 6.4749269999 & 10.468872552 \\ \mathrm{C} & 2.5340923239 & 7.7826390394 & 6.5890528056 \\ \mathrm{C} & 7.1720120447 & 8.1347478271 & 6.62933298 \\ \mathrm{H} & 10.6373356232 & 10.2435915978 & 7.8877647334 \\ \mathrm{H} & 7.0102188312 & 7.3601696288 & 5.8831120423 \\ \mathrm{H} & 11.6914778614 & 11.0263314967 & 9.0847675295 \\ \mathrm{H} & 10.2558189814 & 11.8787303525 & 8.4604391761 \\ \mathrm{H} & 4.7361303315 & 9.1646356738 & 6.7627253461 \\ \mathrm{H} & 7.1036567971 & 9.1100731293 & 6.1394826031 \\ \mathrm{H} & 6.2155080147 & 10.132096717 & 8.401224325 \\ \mathrm{H} & 5.741489257 & 8.9895890546 & 9.6602874958 \\ \mathrm{H} & 9.4249510057 & 12.2549780072 & 10.8046958804 \\ \mathrm{H} & 10.8344702541 & 11.3992184353 & 11.4810128513 \\ \mathrm{H} & 9.1896354241 & 10.889165161 & 11.9117042414 \\ \mathrm{H} & 4.5649087821 & 7.7677109671 & 4.6332903262 \\ \mathrm{H} & 3.7036614459 & 6.2217404663 & 4.7779873996 \\ \mathrm{H} & 5.3925836677 & 6.3335383942 & 5.2650741118 \\ \mathrm{H} & 6.06938534 & 3.8571142321 & 8.7848839219 \\ \mathrm{H} & 4.3212236641 & 3.9421328344 & 9.0111861033 \\ \mathrm{H} & 5.4085733023 & 4.6555472597 & 10.2142588616 \\ \mathrm{H} & 9.8942369469 & 5.9699412662 & 11.2958846038 \\ \mathrm{H} & 11.4348053556 & 6.661588576 & 10.7699384693 \\ \mathrm{H} & 10.4061730566 & 5.784342555 & 9.6190246782 \\ \mathrm{H} & 1.8737048058 & 7.0131403704 & 6.1889588088 \\ \mathrm{H} & 2.4817852977 & 8.6578220578 & 5.9340239446 \\ \mathrm{H} & & & \\ \mathrm{H} & & & \\ \mathrm{H} & & & \\ \mathrm{H} & & & \end{array}$


Rotatory Strengths $(\mathrm{R})$ in cgs (10**-40 erg-esu-cm/Gauss)

\begin{tabular}{|c|c|c|c|c|}
\hline state & $\mathrm{XX}$ & YY & $\mathrm{ZZ}$ & R(length) \\
\hline 1 & 45.9769 & 3.1301 & -5.6819 & 14.4750 \\
\hline 2 & -106.6170 & 7.1567 & -4.9855 & -34.8153 \\
\hline 3 & -34.1674 & -6.6954 & -98.0461 & -46.3030 \\
\hline 4 & 77.5416 & -5.5180 & -0.2459 & 23.9259 \\
\hline 5 & -5.1916 & 8.5123 & 0.9332 & 1.4179 \\
\hline 6 & 9.8800 & 6.5889 & -55.7444 & -13.0918 \\
\hline 7 & 14.0185 & 25.2569 & 5.4882 & 14.9212 \\
\hline 8 & -18.4284 & -5.9986 & 18.7514 & -1.8919 \\
\hline 9 & -87.2626 & -23.6764 & 10.3386 & -33.5335 \\
\hline 10 & -13.7508 & 0.2623 & -8.8523 & -7.4469 \\
\hline 11 & 31.9444 & 0.0568 & -6.2193 & 8.5940 \\
\hline 12 & 11.3685 & 4.6942 & -2.0699 & 4.6643 \\
\hline 13 & 82.8967 & -0.7588 & -33.0225 & 16.3718 \\
\hline 14 & -38.5994 & 52.3130 & 36.2843 & 16.6660 \\
\hline 15 & 10.7003 & 15.1371 & 4.5813 & 10.1395 \\
\hline 16 & -1.0670 & -3.5140 & -2.2531 & -2.2780 \\
\hline 17 & -0.0989 & -31.8523 & -1.3499 & -11.1004 \\
\hline 18 & -7.5375 & -48.3767 & -9.3627 & -21.7590 \\
\hline 19 & -0.0002 & -0.5935 & 9.5912 & 2.9991 \\
\hline 20 & 151.6976 & 100.2528 & 10.9967 & 87.6490 \\
\hline 21 & 6.9482 & -22.5108 & -7.2017 & -7.5881 \\
\hline 22 & -49.7173 & 14.1166 & 1.8370 & -11.2546 \\
\hline 23 & 36.4804 & -10.0478 & 8.4534 & 11.6286 \\
\hline 24 & -14.7652 & 3.3711 & -7.2032 & -6.1991 \\
\hline 25 & 54.2857 & -7.4467 & 7.2860 & 18.0417 \\
\hline 26 & 192.4420 & -2.7532 & -5.2352 & 61.4845 \\
\hline 27 & 18.5199 & -3.1226 & 18.8296 & 11.4090 \\
\hline 28 & -88.3521 & -4.8444 & -10.4576 & -34.5514 \\
\hline 29 & -11.2081 & -2.5554 & -2.6545 & -5.4727 \\
\hline 30 & 5.4782 & -2.1569 & 0.7671 & 1.3628 \\
\hline 31 & 51.9381 & -8.6676 & -21.7354 & 7.1784 \\
\hline 32 & 81.4646 & 2.3475 & -16.5430 & 22.4230 \\
\hline 33 & 46.7397 & 7.2302 & -21.3386 & 10.8771 \\
\hline 34 & 9.8028 & -41.3594 & 42.1805 & 3.5413 \\
\hline 35 & -127.3153 & 19.3708 & 22.2237 & -28.5736 \\
\hline 36 & -8.4715 & -2.6493 & 9.1683 & -0.6508 \\
\hline 37 & -1.8197 & -21.9988 & 20.9718 & -0.9489 \\
\hline 38 & -41.0417 & 12.9959 & -0.1727 & -9.4061 \\
\hline 39 & -66.1031 & 19.5483 & 0.4663 & -15.3628 \\
\hline 40 & -48.2829 & -21.4650 & 90.8482 & 7.0334 \\
\hline
\end{tabular}


The calculated excited states of (-)-1

\begin{tabular}{|c|c|c|c|c|c|c|}
\hline Excited State & 1: & Singlet-A & $2.9713 \mathrm{eV}$ & $417.27 \mathrm{~nm}$ & $\mathrm{f}=0.0017$ & $<\mathrm{S} * * 2>=0.000$ \\
\hline Excited State & 2: & Singlet-A & $3.3920 \mathrm{eV}$ & $365.52 \mathrm{~nm}$ & $\mathrm{f}=0.0196$ & $<\mathrm{S} * * 2>=0.000$ \\
\hline Excited State & 3: & Singlet-A & $3.5516 \mathrm{eV}$ & $349.10 \mathrm{~nm}$ & $\mathrm{f}=0.4109$ & $<\mathrm{S} * * 2>=0.000$ \\
\hline Excited State & 4: & Singlet-A & $3.8016 \mathrm{eV}$ & $326.13 \mathrm{~nm}$ & $\mathrm{f}=0.0054$ & $<\mathrm{S} * * 2>=0.000$ \\
\hline Excited State & 5: & Singlet-A & $4.1042 \mathrm{eV}$ & $302.09 \mathrm{~nm}$ & $\mathrm{f}=0.0020$ & $<\mathrm{S} * * 2>=0.000$ \\
\hline Excited State & $6:$ & Singlet-A & $4.3995 \mathrm{eV}$ & $281.81 \mathrm{~nm}$ & $\mathrm{f}=0.2110$ & $<\mathrm{S} * * 2>=0.000$ \\
\hline Excited State & 7: & Singlet-A & $4.4595 \mathrm{eV}$ & $278.02 \mathrm{~nm}$ & $\mathrm{f}=0.0128$ & $<\mathrm{S} * * 2>=0.000$ \\
\hline Excited State & 8: & Singlet-A & $4.6159 \mathrm{eV}$ & $268.61 \mathrm{~nm}$ & $\mathrm{f}=0.0644$ & $<\mathrm{S} * * 2>=0.000$ \\
\hline Excited State & 9: & Singlet-A & $4.6644 \mathrm{eV}$ & $265.81 \mathrm{~nm}$ & $\mathrm{f}=0.0587$ & $<\mathrm{S} * * 2>=0.000$ \\
\hline Excited State & 10: & Singlet-A & $4.7517 \mathrm{eV}$ & $260.92 \mathrm{~nm}$ & $\mathrm{f}=0.0011$ & $<\mathrm{S} * * 2>=0.000$ \\
\hline Excited State & 11: & Singlet-A & $5.3525 \mathrm{eV}$ & $231.64 \mathrm{~nm}$ & $\mathrm{f}=0.0226$ & $<\mathrm{S} * * 2>=0.000$ \\
\hline Excited State & 12: & Singlet-A & $5.4335 \mathrm{eV}$ & $228.18 \mathrm{~nm}$ & $\mathrm{f}=0.0278$ & $<\mathrm{S}^{* *} 2>=0.000$ \\
\hline Excited State & 13: & Singlet-A & $5.6031 \mathrm{eV}$ & $221.28 \mathrm{~nm}$ & $\mathrm{f}=0.0803$ & $<\mathrm{S}^{* *} 2>=0.000$ \\
\hline Excited State & 14: & Singlet-A & $5.8043 \mathrm{eV}$ & $213.61 \mathrm{~nm}$ & $\mathrm{f}=0.0493$ & $<\mathrm{S} * * 2>=0.000$ \\
\hline Excited State & 15: & Singlet-A & $5.9370 \mathrm{eV}$ & $208.83 \mathrm{~nm}$ & $\mathrm{f}=0.0092$ & $<\mathrm{S} * * 2>=0.000$ \\
\hline Excited State & 16: & Singlet-A & $5.9883 \mathrm{eV}$ & $207.04 \mathrm{~nm}$ & $\mathrm{f}=0.0030$ & $<\mathrm{S} * * 2>=0.000$ \\
\hline Excited State & 17: & Singlet-A & $6.0324 \mathrm{eV}$ & $205.53 \mathrm{~nm}$ & $\mathrm{f}=0.0033$ & $<\mathrm{S}^{* *} 2>=0.000$ \\
\hline Excited State & 18: & Singlet-A & $6.0856 \mathrm{eV}$ & $203.73 \mathrm{~nm}$ & $\mathrm{f}=0.0595$ & $<\mathrm{S} * * 2>=0.000$ \\
\hline Excited State & 19: & Singlet-A & $6.2568 \mathrm{eV}$ & $198.16 \mathrm{~nm}$ & $\mathrm{f}=0.0019$ & $<\mathrm{S} * * 2>=0.000$ \\
\hline Excited State & 20: & Singlet-A & $6.3530 \mathrm{eV}$ & $195.16 \mathrm{~nm}$ & $\mathrm{f}=0.0973$ & $<\mathrm{S} * * 2>=0.000$ \\
\hline Excited State & 21: & Singlet-A & $6.4542 \mathrm{eV}$ & $192.10 \mathrm{~nm}$ & $\mathrm{f}=0.0102$ & $<\mathrm{S} * * 2>=0.000$ \\
\hline Excited State & 22: & Singlet-A & $6.5115 \mathrm{eV}$ & $190.41 \mathrm{~nm}$ & $\mathrm{f}=0.0118$ & $<\mathrm{S} * * 2>=0.000$ \\
\hline Excited State & 23: & Singlet-A & $6.5819 \mathrm{eV}$ & $188.37 \mathrm{~nm}$ & $\mathrm{f}=0.0078$ & $<\mathrm{S} * * 2>=0.000$ \\
\hline Excited State & $24:$ & Singlet-A & $6.6031 \mathrm{eV}$ & $187.77 \mathrm{~nm}$ & $\mathrm{f}=0.0130$ & $<\mathrm{S} * * 2>=0.000$ \\
\hline Excited State & $25:$ & Singlet-A & $6.6682 \mathrm{eV}$ & $185.93 \mathrm{~nm}$ & $\mathrm{f}=0.0061$ & $<\mathrm{S}^{* *} 2>=0.000$ \\
\hline Excited State & 26: & Singlet-A & $6.7632 \mathrm{eV}$ & $183.32 \mathrm{~nm}$ & $\mathrm{f}=0.0204$ & $<\mathrm{S}^{* *} 2>=0.000$ \\
\hline Excited State & 27: & Singlet-A & $6.7748 \mathrm{eV}$ & $183.01 \mathrm{~nm}$ & $\mathrm{f}=0.0032$ & $<\mathrm{S} * * 2>=0.000$ \\
\hline Excited State & $28:$ & Singlet-A & $6.8238 \mathrm{eV}$ & $181.69 \mathrm{~nm}$ & $\mathrm{f}=0.0090$ & $<\mathrm{S} * * 2>=0.000$ \\
\hline Excited State & 29: & Singlet-A & $6.8452 \mathrm{eV}$ & $181.13 \mathrm{~nm}$ & $\mathrm{f}=0.0129$ & $<\mathrm{S} * * 2>=0.000$ \\
\hline Excited State & 30: & Singlet-A & $6.8575 \mathrm{eV}$ & $180.80 \mathrm{~nm}$ & $\mathrm{f}=0.0068$ & $<\mathrm{S} * * 2>=0.000$ \\
\hline Excited State & 31: & Singlet-A & $6.8955 \mathrm{eV}$ & $179.81 \mathrm{~nm}$ & $\mathrm{f}=0.0125$ & $<\mathrm{S} * * 2>=0.000$ \\
\hline Excited State & $32:$ & Singlet-A & $6.9278 \mathrm{eV}$ & $178.97 \mathrm{~nm}$ & $\mathrm{f}=0.0097$ & $<\mathrm{S} * * 2>=0.000$ \\
\hline Excited State & 33: & Singlet-A & $6.9583 \mathrm{eV}$ & $178.18 \mathrm{~nm}$ & $\mathrm{f}=0.0160$ & $<\mathrm{S} * * 2>=0.000$ \\
\hline Excited State & 34: & Singlet-A & $6.9986 \mathrm{eV}$ & $177.16 \mathrm{~nm}$ & $\mathrm{f}=0.0117$ & $<\mathrm{S} * * 2>=0.000$ \\
\hline Excited State & 35: & Singlet-A & $7.0260 \mathrm{eV}$ & $176.46 \mathrm{~nm}$ & $\mathrm{f}=0.0970$ & $<\mathrm{S} * * 2>=0.000$ \\
\hline Excited State & 36: & Singlet-A & $7.0903 \mathrm{eV}$ & $174.86 \mathrm{~nm}$ & $\mathrm{f}=0.0028$ & $<\mathrm{S} * * 2>=0.000$ \\
\hline Excited State & 37: & Singlet-A & $7.0984 \mathrm{eV}$ & $174.67 \mathrm{~nm}$ & $\mathrm{f}=0.0024$ & $<\mathrm{S} * * 2>=0.000$ \\
\hline Excited State & 38: & Singlet-A & $7.1239 \mathrm{eV}$ & $174.04 \mathrm{~nm}$ & $\mathrm{f}=0.1056$ & $<\mathrm{S}^{* *} 2>=0.000$ \\
\hline Excited State & 39: & Singlet-A & $7.1735 \mathrm{eV}$ & $172.84 \mathrm{~nm}$ & $\mathrm{f}=0.0138$ & $<\mathrm{S} * * 2>=0.000$ \\
\hline Excited State & 40: & Singlet-A & $7.2383 \mathrm{eV}$ & $171.29 \mathrm{~nm}$ & $\mathrm{f}=0.0638$ & $<\mathrm{S}^{* * 2}>=0.000$ \\
\hline
\end{tabular}


Conformer 1 of $(+)-2$ (94.54\%)

The coordinates of conformer 1 of $(+)-2$

$\mathrm{C}$

$\mathrm{C}$

C

$\mathrm{O}$

$\mathrm{C}$

C

C

C

C

$\mathrm{N}$

$\mathrm{S}$

C

C

$\mathrm{C}$

C

C

C

C

$\mathrm{C}$

$\mathrm{O}$

$\mathrm{C}$

$\mathrm{C}$

$\mathrm{N}$

C

C

$\mathrm{C}$

$\mathrm{O}$

C

$\mathrm{C}$

$\mathrm{C}$

C

$\mathrm{N}$

$\mathrm{S}$

C

C

C

C

C

C

$\mathrm{O}$

C
1.4886600799

2.3427167644

1.6379687363

3.5670011462

1.4345235882

2.4960502825

0.1605231254

2.1508645002

$-0.3418849843$

0.3204946598

$-0.9264830612$

$-1.6362534147$

$-2.8092081826$

$-3.0542637831$

$-2.4567403643$

$-3.2673689276$

$-4.6285406728$

$-2.8714444555$

$-5.0882596612$

$-5.4012233713$

$-5.8777337569$

$-6.0205055379$

$-3.9132665424$

2.9220503004

4.3832796371

5.1085141347

5.0170282358

5.8276747723

6.1338700239

2.2867558705

3.0334574863

4.294756503

0.5425734394

2.2581216946

0.9563806213

$-0.0162877327$

$-1.3051800536$

$-1.867842439$

$-0.963788295$

$-3.0648621719$

$-1.2591645269$
$-2.42307363$

$-2.1836976429$

$-2.0365761164$

$-2.2012995726$

$-3.4740084662$

$-1.2321045252$

$-2.1497726229$

$-2.8788306945$

$-1.4774486613$

$-1.4191342221$

$-2.5835883423$

$-0.7281927899$

$-1.4881955779$

$-2.8011847099$

$-1.7831677108$

$-1.5269183122$

$-0.9939436927$

$-1.7786074637$

$-0.7294937524$

$-0.8115164909$

0.5843186314

$-1.8963587976$

$-0.5372049189$

$-0.5273586731$

$-0.5862709775$

0.600511591

$-1.5688090635$

0.102771355

1.1217369487

0.6174989683

1.749579173

1.7369736848

0.7470917994

2.9698079137

2.6391626389

2.0530587811

2.4582432632

3.4287245074

4.0398254106

3.6996251051

5.5407010567
0.0991160133

1.2743737207

2.6199942389

1.1927818648

3.1609663423

3.5987198414

0.2330361994

$-1.1716237705$

1.4504235851

2.5438175071

$-1.0831212936$

1.3605442232

0.7077069946

1.4854773904

$-0.7311760121$

$-1.7885275409$

$-1.5561482574$

$-3.2166233608$

$-0.1248758811$

$-2.4901325331$

$-0.0797735947$

0.273331176

0.7222446082

$-1.6841082419$

$-1.5282932051$

$-0.8998216385$

$-1.9042786916$

0.3677262808

$-1.9248575302$

$-1.3071246074$

$-0.7138663915$

$-0.5073129225$

$-1.5742777189$

$-0.3016060059$

0.4656149415

$-0.5310556095$

$-0.6686007066$

0.2868545764

1.3524884305

0.2691121177

1.4608522102 


\begin{tabular}{|c|c|c|c|}
\hline $\mathrm{C}$ & -1.3295765317 & 3.3590876666 & 2.6931426543 \\
\hline $\mathrm{N}$ & 0.4321080516 & 3.9174189499 & 0.9286026252 \\
\hline $\mathrm{C}$ & 2.2532816105 & -1.7550266418 & -2.2322985138 \\
\hline $\mathrm{C}$ & -2.2762432134 & 1.8932588213 & -1.6624613271 \\
\hline $\mathrm{C}$ & 1.2776665055 & 1.63396339 & 1.5928724448 \\
\hline $\mathrm{H}$ & 2.404151589 & -3.9669316918 & 3.2803692374 \\
\hline $\mathrm{H}$ & 0.8147218904 & -4.0650862194 & 2.4795162754 \\
\hline $\mathrm{H}$ & 0.9365463265 & -3.4207019415 & 4.1337786243 \\
\hline $\mathrm{H}$ & 3.4683020537 & -1.7113837708 & 3.7321303391 \\
\hline $\mathrm{H}$ & 2.6623478075 & -0.2167632692 & 3.2284082543 \\
\hline $\mathrm{H}$ & 1.9860503629 & -1.1716090391 & 4.5643240836 \\
\hline $\mathrm{H}$ & 3.1600004834 & -3.2185438109 & -0.9294556457 \\
\hline $\mathrm{H}$ & 1.6099210117 & -3.7257438354 & -1.6112822166 \\
\hline $\mathrm{H}$ & -1.4676415363 & 0.1845057872 & 0.7750285478 \\
\hline $\mathrm{H}$ & -1.9196875257 & -0.4229430065 & 2.3729698405 \\
\hline $\mathrm{H}$ & -2.1379176945 & -3.3964150132 & 1.5616935945 \\
\hline $\mathrm{H}$ & -3.3845044999 & -2.559995558 & 2.50158531 \\
\hline $\mathrm{H}$ & -3.8140095493 & -3.4203971585 & 1.0069394078 \\
\hline $\mathrm{H}$ & -2.8297047762 & -2.8511997294 & -3.4432505704 \\
\hline $\mathrm{H}$ & -3.6047246604 & -1.3244444971 & -3.8854111928 \\
\hline $\mathrm{H}$ & -1.8829847083 & -1.3561726929 & -3.4304036911 \\
\hline $\mathrm{H}$ & -6.7118020523 & 0.5520907085 & -0.7844428626 \\
\hline $\mathrm{H}$ & -5.2275501364 & 1.4287946676 & -0.3275636004 \\
\hline $\mathrm{H}$ & -6.2782911956 & 0.7414580004 & 0.9286933438 \\
\hline $\mathrm{H}$ & -5.5554716597 & -2.8720875506 & 0.1106081201 \\
\hline $\mathrm{H}$ & -6.2841035356 & -1.8106262559 & 1.3334392716 \\
\hline $\mathrm{H}$ & -6.9389113845 & -1.8610984537 & -0.3210472608 \\
\hline $\mathrm{H}$ & -4.2036082767 & -0.3709641368 & 1.6828036007 \\
\hline $\mathrm{H}$ & 6.4943671446 & -0.7228708221 & 0.1040311871 \\
\hline $\mathrm{H}$ & 5.1031833733 & -0.2577362383 & 1.1030668929 \\
\hline $\mathrm{H}$ & 6.4099483094 & 0.9206141355 & 0.8024986636 \\
\hline $\mathrm{H}$ & 6.7987608056 & 0.3058045329 & -2.2210466052 \\
\hline $\mathrm{H}$ & 5.627770602 & 1.5065477924 & -2.8165957802 \\
\hline $\mathrm{H}$ & 6.7210150899 & 1.9301608756 & -1.4794562165 \\
\hline $\mathrm{H}$ & 1.9944665993 & 3.5692402458 & -1.1823057926 \\
\hline $\mathrm{H}$ & 2.9100731078 & 3.5776235715 & 0.3326760793 \\
\hline $\mathrm{H}$ & -2.3165287239 & 5.7058876669 & 1.6808451091 \\
\hline $\mathrm{H}$ & -1.0050137427 & 6.0463121093 & 0.5243870238 \\
\hline $\mathrm{H}$ & -0.6607085018 & 5.9806888544 & 2.2671852321 \\
\hline $\mathrm{H}$ & -1.3270563812 & 2.2680936692 & 2.6228213796 \\
\hline $\mathrm{H}$ & -0.6149347885 & 3.6585525959 & 3.4678251583 \\
\hline $\mathrm{H}$ & -2.3335330134 & 3.6650778174 & 3.0027424985 \\
\hline $\mathrm{H}$ & 1.0411585143 & 4.2830443624 & 1.6570512633 \\
\hline $\mathrm{H}$ & 2.8525048275 & -2.1361627302 & -3.0652646059 \\
\hline
\end{tabular}




$\begin{array}{llll}\mathrm{H} & 1.2601001279 & -1.5222321406 & -2.626118568 \\ \mathrm{H} & -2.8658797131 & 1.0993564336 & -1.1898094639 \\ \mathrm{H} & -2.9755414873 & 2.6690920673 & -1.9836892838 \\ \mathrm{H} & -1.7852668134 & 1.4744377057 & -2.5453416627 \\ \mathrm{H} & 1.7183691259 & 0.7109134162 & 1.2044705651 \\ \mathrm{H} & 2.0039888094 & 2.0860786721 & 2.277064297 \\ \mathrm{H} & 0.391822305 & 1.3545662873 & 2.1600181865\end{array}$

Rotatory Strengths (R) in cgs $\left(10^{* *}-40\right.$ erg-esu-cm/Gauss)

$\begin{array}{rrrrc}\text { state } & \mathrm{XX} & \mathrm{YY} & \mathrm{ZZ} & \mathrm{R}(\text { length) } \\ 1 & -39.8961 & -24.9809 & 2.3053 & -20.8572 \\ 2 & -82.8512 & -13.6426 & 0.0631 & -32.1436 \\ 3 & -6.2557 & 65.1296 & 187.3270 & 82.0670 \\ 4 & 94.2442 & 106.8960 & 222.4228 & 141.1877 \\ 5 & -23.4070 & 18.1902 & 43.8540 & 12.8791 \\ 6 & 70.8262 & 43.4633 & 6.4960 & 40.2618 \\ 7 & -741.7957 & 219.2864 & 106.4899 & -138.6731 \\ 8 & -28.6824 & 37.7272 & 61.2037 & 23.4162 \\ 9 & -16.4222 & 130.6679 & 83.8050 & 66.0169 \\ 10 & 1.6954 & -3.0268 & 1.1749 & -0.0522 \\ 11 & -52.9250 & 7.8180 & -6.2280 & -17.1117 \\ 12 & -173.8853 & -7.5617 & 9.1266 & -57.4401 \\ 13 & 2.6385 & 6.3002 & 0.5113 & 3.1500 \\ 14 & -3.4012 & 6.4168 & -2.0389 & 0.3256 \\ 15 & -9.4255 & 6.4178 & 55.4343 & 17.4756 \\ 16 & 2.1148 & -14.7150 & 4.2047 & -2.7985 \\ 17 & -27.7053 & -0.1529 & 96.8747 & 23.0055 \\ 18 & -27.3741 & 13.5564 & 105.2057 & 30.4627 \\ 19 & 35.5919 & 4.6788 & 95.8241 & 45.3649 \\ 20 & -117.3475 & -5.1113 & -21.4638 & -47.9742 \\ 21 & -462.6875 & 264.7566 & 27.5340 & -56.7990 \\ 22 & -0.5677 & -19.6998 & 3.7864 & -5.4937 \\ 23 & -18.7580 & 20.1195 & 11.7378 & 4.3664 \\ 24 & 115.6349 & -44.4811 & 15.3073 & 28.8204 \\ 25 & -1.3172 & 0.3117 & 3.1661 & 0.7202 \\ 26 & -153.1510 & 30.0918 & 1.0344 & -40.6749 \\ 27 & 12.9764 & 3.9252 & 79.0820 & 31.9945 \\ 28 & -30.1066 & -0.7119 & 92.7851 & 20.6555 \\ 29 & -0.0147 & 7.2369 & 20.1303 & 9.1175 \\ 30 & -43.2083 & 7.8258 & 10.6489 & -8.2446 \\ 31 & 81.0140 & 5.0545 & -4.7021 & 27.1222 \\ 32 & 30.2292 & -20.1257 & -15.8964 & -1.9310 \\ 33 & -56.4473 & -12.5259 & -24.1033 & -31.0255 \\ 34 & 22.9422 & -2.8625 & 6.5552 & 8.8783\end{array}$




$\begin{array}{lrrrc}35 & 43.9654 & -16.3357 & -0.4876 & 9.0474 \\ 36 & 5.3648 & -0.6392 & -0.6857 & 1.3466 \\ 37 & 0.9464 & -0.4191 & 1.3249 & 0.6174 \\ 38 & -40.5678 & 0.6137 & 26.5823 & -4.4573 \\ 39 & 0.0102 & -0.0350 & 5.0534 & 1.6762 \\ 40 & -25.8389 & 10.3461 & -0.9591 & -5.4839 \\ 41 & 5.7371 & -2.4927 & -0.4487 & 0.9319 \\ 42 & -0.2936 & 0.1626 & -1.2460 & -0.4590 \\ 43 & -62.0453 & 16.0670 & -13.4673 & -19.8152 \\ 44 & -14.9538 & 36.5238 & 15.6531 & 12.4077 \\ 45 & -130.7141 & -7.5821 & 244.1681 & 35.2906 \\ 46 & 58.3974 & 19.0642 & -15.6708 & 20.5969 \\ 47 & -31.5747 & 34.2911 & -0.0938 & 0.8742 \\ 48 & -118.9674 & 30.6871 & -5.9298 & -31.4033 \\ 49 & 1.4669 & 5.4403 & 24.4062 & 10.4378 \\ 50 & -23.5130 & -21.9708 & 6.3139 & -13.0566 \\ 51 & 20.2719 & 8.8040 & -0.1614 & 9.6381 \\ 52 & 2.5474 & 17.5756 & 4.2862 & 8.1364 \\ 53 & -16.5154 & -40.7404 & 5.9985 & -17.0858 \\ 54 & 6.8936 & -81.6793 & 24.2375 & -16.8494 \\ 55 & -175.7109 & 10.2873 & 22.8724 & -47.5171 \\ 56 & -4.0777 & 6.2421 & -9.0204 & -2.2853 \\ 57 & -0.5227 & 8.4434 & 1.7030 & 3.2079 \\ 58 & -53.2129 & 12.0597 & 101.9276 & 20.2582 \\ 59 & -6.9020 & -0.0114 & 14.7906 & 2.6257 \\ 60 & 7.1972 & -3.4775 & 25.2273 & 9.6490\end{array}$

The calculated excited states of conformer 1 of (+)-2

$\begin{array}{lllllll}\text { Excited State } & \text { 1: } & \text { Singlet-A } & 2.9082 \mathrm{eV} & 426.33 \mathrm{~nm} & \mathrm{f}=0.0027 & <\mathrm{S}^{* *} 2>=0.000 \\ \text { Excited State } & \text { 2: } & \text { Singlet-A } & 2.9635 \mathrm{eV} & 418.36 \mathrm{~nm} & \mathrm{f}=0.0026 & <\mathrm{S}^{* *} 2>=0.000 \\ \text { Excited State } & \text { 3: } & \text { Singlet-A } & 3.1288 \mathrm{eV} & 396.27 \mathrm{~nm} & \mathrm{f}=0.0108 & <\mathrm{S}^{* *} 2>=0.000 \\ \text { Excited State } & \text { 4: } & \text { Singlet-A } & 3.2920 \mathrm{eV} & 376.62 \mathrm{~nm} & \mathrm{f}=0.0402 & <\mathrm{S}^{* *} 2>=0.000 \\ \text { Excited State } & \text { 5: } & \text { Singlet-A } & 3.3397 \mathrm{eV} & 371.24 \mathrm{~nm} & \mathrm{f}=0.0187 & <\mathrm{S}^{* *} 2>=0.000 \\ \text { Excited State } & \text { 6: } & \text { Singlet-A } & 3.3916 \mathrm{eV} & 365.56 \mathrm{~nm} & \mathrm{f}=0.0260 & <\mathrm{S}^{* *} 2>=0.000 \\ \text { Excited State } & \text { 7: } & \text { Singlet-A } & 3.5171 \mathrm{eV} & 352.52 \mathrm{~nm} & \mathrm{f}=0.4239 & <\mathrm{S}^{* *} 2>=0.000 \\ \text { Excited State } & \text { 8: } & \text { Singlet-A } & 3.5366 \mathrm{eV} & 350.57 \mathrm{~nm} & \mathrm{f}=0.0158 & <\mathrm{S}^{* *} 2>=0.000 \\ \text { Excited State } & \text { 9: } & \text { Singlet-A } & 3.5856 \mathrm{eV} & 345.78 \mathrm{~nm} & \mathrm{f}=0.0338 & <\mathrm{S}^{* *} 2>=0.000 \\ \text { Excited State } & 10: & \text { Singlet-A } & 3.6712 \mathrm{eV} & 337.72 \mathrm{~nm} & \mathrm{f}=0.0016 & <\mathrm{S}^{* *} 2>=0.000 \\ \text { Excited State } & 11: & \text { Singlet-A } & 3.6824 \mathrm{eV} & 336.69 \mathrm{~nm} & \mathrm{f}=0.0085 & <\mathrm{S}^{* *} 2>=0.000 \\ \text { Excited State } & 12: & \text { Singlet-A } & 3.7423 \mathrm{eV} & 331.31 \mathrm{~nm} & \mathrm{f}=0.0232 & <\mathrm{S} * * 2>=0.000 \\ \text { Excited State } & 13: & \text { Singlet-A } & 3.7741 \mathrm{eV} & 328.51 \mathrm{~nm} & \mathrm{f}=0.0008 & <\mathrm{S}^{* *} 2>=0.000 \\ \text { Excited State } & 14: & \text { Singlet-A } & 3.8106 \mathrm{eV} & 325.36 \mathrm{~nm} & \mathrm{f}=0.0023 & <\mathrm{S}^{* *} 2>=0.000 \\ \text { Excited State } & 15: & \text { Singlet-A } & 3.9370 \mathrm{eV} & 314.92 \mathrm{~nm} & \mathrm{f}=0.0072 & <\mathrm{S}^{* *} 2>=0.000 \\ \text { Excited State } & 16: & \text { Singlet-A } & 4.0655 \mathrm{eV} & 304.97 \mathrm{~nm} & \mathrm{f}=0.0022 & <\mathrm{S}^{* *} 2>=0.000\end{array}$




\begin{tabular}{|c|c|c|c|c|c|c|}
\hline Excited State & 17: & Singlet-A & $4.1014 \mathrm{eV}$ & $302.30 \mathrm{~nm}$ & $f=0.0076$ & $<\mathrm{S} * * 2>=0.000$ \\
\hline Excited State & 18: & Singlet-A & $4.2326 \mathrm{eV}$ & $292.93 \mathrm{~nm}$ & $f=0.0167$ & $<\mathrm{S} * * 2>=0.000$ \\
\hline Excited State & 19: & Singlet-A & $4.2429 \mathrm{eV}$ & $292.21 \mathrm{~nm}$ & $\mathrm{f}=0.0464$ & $<\mathrm{S} * * 2>=0.000$ \\
\hline Excited State & 20: & Singlet-A & $4.2862 \mathrm{eV}$ & $289.27 \mathrm{~nm}$ & $\mathrm{f}=0.0524$ & $<\mathrm{S} * * 2>=0.000$ \\
\hline Excited State & 21: & Singlet-A & $4.3144 \mathrm{eV}$ & $287.37 \mathrm{~nm}$ & $\mathrm{f}=0.2473$ & $<\mathrm{S} * * 2>=0.000$ \\
\hline Excited State & 22: & Singlet-A & $4.3910 \mathrm{eV}$ & $282.36 \mathrm{~nm}$ & $\mathrm{f}=0.0071$ & $<\mathrm{S} * * 2>=0.000$ \\
\hline Excited State & 23: & Singlet-A & $4.4402 \mathrm{eV}$ & $279.23 \mathrm{~nm}$ & $\mathrm{f}=0.0086$ & $<\mathrm{S} * * 2>=0.000$ \\
\hline Excited State & 24: & Singlet-A & $4.4719 \mathrm{eV}$ & $277.25 \mathrm{~nm}$ & $\mathrm{f}=0.0237$ & $<\mathrm{S} * * 2>=0.000$ \\
\hline Excited State & 25: & Singlet-A & $4.4781 \mathrm{eV}$ & $276.87 \mathrm{~nm}$ & $\mathrm{f}=0.0025$ & $<\mathrm{S}^{* *} 2>=0.000$ \\
\hline Excited State & 26: & Singlet-A & $4.4841 \mathrm{eV}$ & $276.50 \mathrm{~nm}$ & $f=0.0397$ & $<\mathrm{S} * * 2>=0.000$ \\
\hline Excited State & 27: & Singlet-A & $4.5104 \mathrm{eV}$ & $274.88 \mathrm{~nm}$ & $\mathrm{f}=0.0123$ & $<\mathrm{S} * * 2>=0.000$ \\
\hline Excited State & 28: & Singlet-A & $4.5619 \mathrm{eV}$ & $271.78 \mathrm{~nm}$ & $\mathrm{f}=0.0462$ & $<\mathrm{S} * * 2>=0.000$ \\
\hline Excited State & 29: & Singlet-A & $4.5809 \mathrm{eV}$ & $270.66 \mathrm{~nm}$ & $\mathrm{f}=0.0089$ & $<\mathrm{S} * * 2>=0.000$ \\
\hline Excited State & 30: & Singlet-A & $4.5976 \mathrm{eV}$ & $269.67 \mathrm{~nm}$ & $\mathrm{f}=0.0182$ & $<\mathrm{S} * * 2>=0.000$ \\
\hline Excited State & 31: & Singlet-A & $4.6575 \mathrm{eV}$ & $266.20 \mathrm{~nm}$ & $\mathrm{f}=0.0396$ & $<\mathrm{S} * * 2>=0.000$ \\
\hline Excited State & 32: & Sing & $4.6780 \mathrm{eV}$ & $265.04 \mathrm{~nm}$ & $\mathrm{f}=0.0140$ & $<\mathrm{S} * * 2>=0.000$ \\
\hline Excited State & 33: & Singlet-A & $4.6876 \mathrm{eV}$ & $264.49 \mathrm{~nm}$ & $\mathrm{f}=0.0472$ & $<\mathrm{S} * * 2>=0.000$ \\
\hline Excited State & 34: & Singlet-A & $4.7444 \mathrm{eV}$ & $261.33 \mathrm{~nm}$ & $\mathrm{f}=0.0087$ & $<\mathrm{S} * * 2>=0.000$ \\
\hline Excited State & 35: & Singlet-A & $4.7460 \mathrm{eV}$ & $261.24 \mathrm{~nm}$ & $\mathrm{f}=0.0076$ & $<\mathrm{S} * * 2>=0.000$ \\
\hline Excited State & 36: & Singlet-A & $4.8662 \mathrm{eV}$ & $254.79 \mathrm{~nm}$ & $\mathrm{f}=0.0006$ & $<\mathrm{S} * * 2>=0.000$ \\
\hline Excited State & $37:$ & Singlet-A & $5.0589 \mathrm{eV}$ & $245.08 \mathrm{~nm}$ & $\mathrm{f}=0.0002$ & $<\mathrm{S} * * 2>=0.000$ \\
\hline Excited State & 38: & Singlet-A & $5.0641 \mathrm{eV}$ & $244.83 \mathrm{~nm}$ & $\mathrm{f}=0.0147$ & $<\mathrm{S}^{* *} 2>=0.000$ \\
\hline Excited State & 39: & & $5.1788 \mathrm{eV}$ & $239.41 \mathrm{~nm}$ & $\mathrm{f}=0.0005$ & $<\mathrm{S} * * 2>=0.000$ \\
\hline Excited State & 40: & Singlet-A & $5.2158 \mathrm{eV}$ & $237.71 \mathrm{~nm}$ & $\mathrm{f}=0.0060$ & $<\mathrm{S} * * 2>=0.000$ \\
\hline Excited State & 41: & Singlet-A & $5.2942 \mathrm{eV}$ & $234.19 \mathrm{~nm}$ & $\mathrm{f}=0.0019$ & $<\mathrm{S} * * 2>=0.000$ \\
\hline Excited State & 42: & Singlet-A & $5.3396 \mathrm{eV}$ & $232.20 \mathrm{~nm}$ & $\mathrm{f}=0.0002$ & $<\mathrm{S} * * 2>=0.000$ \\
\hline Excited State & 43: & Singlet-A & $5.3475 \mathrm{eV}$ & $231.85 \mathrm{~nm}$ & $\mathrm{f}=0.0118$ & $<\mathrm{S} * * 2>=0.000$ \\
\hline Excited State & 44: & Singlet-A & $5.3756 \mathrm{eV}$ & $230.64 \mathrm{~nm}$ & $\mathrm{f}=0.0113$ & $<\mathrm{S} * * 2>=0.000$ \\
\hline Excited State & 45: & Singlet-A & $5.3973 \mathrm{eV}$ & $229.72 \mathrm{~nm}$ & $\mathrm{f}=0.0398$ & $<\mathrm{S} * * 2>=0.000$ \\
\hline Excited State & 46: & Singlet-A & $5.4868 \mathrm{eV}$ & $225.97 \mathrm{~nm}$ & $\mathrm{f}=0.0118$ & $<\mathrm{S} * * 2>=0.000$ \\
\hline Excited State & 47: & Singlet-A & $5.5372 \mathrm{eV}$ & $223.91 \mathrm{~nm}$ & $\mathrm{f}=0.0433$ & $<\mathrm{S} * * 2>=0.000$ \\
\hline Excited State & 48: & Singlet-A & $5.5537 \mathrm{eV}$ & $223.25 \mathrm{~nm}$ & $\mathrm{f}=0.0573$ & $<\mathrm{S} * * 2>=0.000$ \\
\hline Excited State & 49: & Singlet-A & $5.5791 \mathrm{eV}$ & $222.23 \mathrm{~nm}$ & $\mathrm{f}=0.0019$ & $<\mathrm{S} * * 2>=0.000$ \\
\hline Excited State & 50: & Singlet-A & $5.5972 \mathrm{eV}$ & $221.51 \mathrm{~nm}$ & $\mathrm{f}=0.0163$ & $<\mathrm{S} * * 2>=0.000$ \\
\hline Excited State & 51: & Singlet-A & $5.6225 \mathrm{eV}$ & $220.51 \mathrm{~nm}$ & $\mathrm{f}=0.0059$ & $<\mathrm{S}^{* *} 2>=0.000$ \\
\hline Excited State & $52:$ & Singlet-A & $5.6440 \mathrm{eV}$ & $219.68 \mathrm{~nm}$ & $\mathrm{f}=0.0085$ & $<\mathrm{S} * * 2>=0.000$ \\
\hline Excited State & 53: & Singlet-A & $5.7192 \mathrm{eV}$ & $216.79 \mathrm{~nm}$ & $\mathrm{f}=0.0275$ & $<\mathrm{S} * * 2>=0.000$ \\
\hline Excited State & 54: & Singlet-A & $5.7306 \mathrm{eV}$ & $216.35 \mathrm{~nm}$ & $\mathrm{f}=0.0091$ & $<\mathrm{S} * * 2>=0.000$ \\
\hline Excited State & 55: & Singlet-A & $5.7854 \mathrm{eV}$ & $214.30 \mathrm{~nm}$ & $\mathrm{f}=0.0541$ & $<\mathrm{S} * * 2>=0.000$ \\
\hline Excited State & $56:$ & Singlet-A & $5.8226 \mathrm{eV}$ & $212.94 \mathrm{~nm}$ & $\mathrm{f}=0.0016$ & $<\mathrm{S} * * 2>=0.000$ \\
\hline Excited State & 57: & Singlet-A & $5.8618 \mathrm{eV}$ & $211.51 \mathrm{~nm}$ & $\mathrm{f}=0.0008$ & $<\mathrm{S} * * 2>=0.000$ \\
\hline Excited State & 58: & Singlet-A & $5.8948 \mathrm{eV}$ & $210.33 \mathrm{~nm}$ & $\mathrm{f}=0.0535$ & $<\mathrm{S} * * 2>=0.000$ \\
\hline Excited State & 59: & Singlet-A & $5.9224 \mathrm{eV}$ & $209.35 \mathrm{~nm}$ & $\mathrm{f}=0.0129$ & $<\mathrm{S}^{* *} 2>=0.000$ \\
\hline Excited State & 60: & Singlet-A & $5.9522 \mathrm{eV}$ & $208.30 \mathrm{~nm}$ & $\mathrm{f}=0.0047$ & $<\mathrm{S} * * 2>=0.000$ \\
\hline
\end{tabular}


Conformer 2 of (+)-2 (4.75\%)

The coordinates of conformer 2 of (+)-2

0.4827917029

1.5230386919

1.113942518

$\mathrm{C}$

1.674559657

2.3283153616

0.7887808509

C $\quad 1.4533437225$

3.7850945464

0.4034764025

1.8642550367

0.9111389305

$\mathrm{C}$

2.8036820124

4.5911124564

1.72571251

4.2745501834

$-0.5124974038$

2.0319709609

0.765048935

0.1629065446

1.6852298878

3.2481581512

$-0.0741977861$

4.0451543762

$-0.2525277992$

1.1640289111

1.2318102947

3.4926862648

$-0.8635827693$

3.3864126543

$-0.0884938603$

4.3937033611

1.0833619481

1.9885750332

0.4622936903

1.3302457251

0.4752588637

1.9910252131

$-0.0682090801$

$-0.0496702057$

1.0440707751

3.294482446

$-0.8520009854$

1.5063274521

0.0934194386

3.0706502571

$-2.228574293$

4.3960302006

$-0.0982102367$

3.5987811863

$-1.105257681$

$-1.3293545864$

$-0.1009613481$

$-2.4071345218$

0.598941289

$-3.0544708678$

$-0.1290656349$

$-2.8231919389$

1.6872503885

$-4.2083566324$

$-0.9728551411$

$-3.6067000458$

0.8736864018

$-0.7856162342$

$-1.1999510965$

$-1.1492140879$

$-1.5337541134$

$-2.1694431192$

$-1.0484044633$

0.4265400678

$-2.1398725487$

$-0.20469699$

$-2.3802335354$

0.2788258077

$-3.6740346155$

1.040800849

$-3.3497104567$

2.1662355894

$-4.0054972757$

2.692564761

$-5.0968374086$

2.1257334545

$-5.3254248553$

3.5908430392

$-5.8294220206$

3.302174267

$-5.2583968343$ 


\begin{tabular}{|c|c|c|c|}
\hline $\mathrm{C}$ & -2.9531805843 & 1.5003529026 & -6.7342710397 \\
\hline $\mathrm{N}$ & -3.2740078619 & 1.2182114681 & -4.2418207732 \\
\hline $\mathrm{C}$ & 1.0604508497 & -0.8627073161 & 0.556586646 \\
\hline $\mathrm{C}$ & 0.6036098335 & 2.9098085877 & -3.6986794809 \\
\hline $\mathrm{C}$ & -1.9595017847 & -0.9381270156 & -4.557347304 \\
\hline $\mathrm{H}$ & 2.4135079464 & 4.4598017428 & 2.2384156864 \\
\hline $\mathrm{H}$ & 0.6481346984 & 4.2595110923 & 2.386303548 \\
\hline $\mathrm{H}$ & 1.3116623401 & 5.651617033 & 1.498055319 \\
\hline $\mathrm{H}$ & 3.5443721151 & 4.172023581 & -0.0144386404 \\
\hline $\mathrm{H}$ & 2.6042421058 & 3.690072412 & -1.4370887803 \\
\hline $\mathrm{H}$ & 2.4094049558 & 5.3248744176 & -0.7664831337 \\
\hline $\mathrm{H}$ & 1.6366350149 & 0.2291185927 & 2.3281509302 \\
\hline $\mathrm{H}$ & -0.0744314051 & -0.2068960957 & 2.2962577845 \\
\hline $\mathrm{H}$ & -2.0944684669 & 2.776250261 & -1.692934445 \\
\hline $\mathrm{H}$ & -1.9724648003 & 4.4898507792 & -1.307658465 \\
\hline $\mathrm{H}$ & -2.4969125173 & 4.248937944 & 1.7286195934 \\
\hline $\mathrm{H}$ & -3.3338038334 & 5.4133972576 & 0.6847207464 \\
\hline $\mathrm{H}$ & -4.2637022064 & 4.2866411371 & 1.702897308 \\
\hline $\mathrm{H}$ & -4.5715435743 & -0.1156998606 & 2.0851044054 \\
\hline $\mathrm{H}$ & -5.9656547628 & -0.3268037313 & 1.0125344863 \\
\hline $\mathrm{H}$ & -4.3415135316 & -0.7819943727 & 0.4583590213 \\
\hline $\mathrm{H}$ & -7.5047212093 & 2.7940267979 & -2.1207858398 \\
\hline $\mathrm{H}$ & -5.9189496594 & 2.2832611709 & -2.7694985902 \\
\hline $\mathrm{H}$ & -6.3876583948 & 3.9924061466 & -2.8180330019 \\
\hline $\mathrm{H}$ & -6.1803688843 & 4.5633914597 & 0.9062997857 \\
\hline $\mathrm{H}$ & -6.507532508 & 5.336898671 & -0.6561523267 \\
\hline $\mathrm{H}$ & -7.6313933731 & 4.1203104104 & -0.0072834306 \\
\hline $\mathrm{H}$ & -4.3123096983 & 4.5393388686 & -1.4817840347 \\
\hline $\mathrm{H}$ & -1.000458817 & -4.9261789214 & -0.3173405457 \\
\hline $\mathrm{H}$ & -0.7826130686 & -3.8261530158 & -1.703344075 \\
\hline $\mathrm{H}$ & -2.3122569568 & -4.7144820105 & -1.507719573 \\
\hline $\mathrm{H}$ & -2.6407650309 & -4.3416284447 & 1.5279661068 \\
\hline $\mathrm{H}$ & -3.5184174888 & -2.8025342285 & 1.4960969905 \\
\hline $\mathrm{H}$ & -3.939421044 & -4.0794723585 & 0.3331588508 \\
\hline $\mathrm{H}$ & -3.2403052339 & 0.6812936049 & -1.7841719824 \\
\hline $\mathrm{H}$ & -3.9346352381 & -0.6994552937 & -2.627528895 \\
\hline $\mathrm{H}$ & -3.656125344 & 4.0519202237 & -6.0175816237 \\
\hline $\mathrm{H}$ & -3.8622620333 & 3.7611688026 & -4.2656062837 \\
\hline $\mathrm{H}$ & -4.9124689754 & 2.9350348385 & -5.4308268902 \\
\hline $\mathrm{H}$ & -2.2353356569 & 0.6842468871 & -6.8471991115 \\
\hline $\mathrm{H}$ & -3.9572132192 & 1.1036415764 & -6.9236088247 \\
\hline $\mathrm{H}$ & -2.7289286698 & 2.2589704334 & -7.4899142709 \\
\hline $\mathrm{H}$ & -4.1306177561 & 0.7257566052 & -4.481652565 \\
\hline $\mathrm{H}$ & 1.7628539962 & -0.4194642086 & -0.155426984 \\
\hline
\end{tabular}




$\begin{array}{llll}\mathrm{H} & 1.5512977802 & -1.7275857164 & 1.0120161515 \\ \mathrm{H} & 1.4884417205 & 2.2648656157 & -3.7629206877 \\ \mathrm{H} & 0.7283272577 & 3.7286142291 & -4.4094793418 \\ \mathrm{H} & 0.5675443598 & 3.3310360424 & -2.6866060353 \\ \mathrm{H} & -1.3426689355 & -1.6601597298 & -4.0100419511 \\ \mathrm{H} & -2.8809261374 & -1.4437385925 & -4.8662289687 \\ \mathrm{H} & -1.4053587729 & -0.6339862892 & -5.4476383453\end{array}$

Rotatory Strengths $(\mathrm{R})$ in $\operatorname{cgs}\left(10^{* *}-40\right.$ erg-esu-cm/Gauss $)$

$\begin{array}{rrrrc}\text { state } & \mathrm{XX} & \mathrm{YY} & \mathrm{ZZ} & \mathrm{R}(\text { length) } \\ 1 & -0.0001 & 396.7403 & -126.3986 & 90.1139 \\ 2 & -92.2128 & 0.0000 & -0.0002 & -30.7377 \\ 3 & -0.0001 & 342.7388 & 68.2054 & 136.9813 \\ 4 & -382.8165 & 0.0000 & -0.0000 & -127.6055 \\ 5 & -26.1977 & -0.0000 & -0.0001 & -8.7326 \\ 6 & -0.0000 & -8.9647 & -21.6143 & -10.1930 \\ 7 & -424.0105 & 0.0001 & -0.0001 & -141.3369 \\ 8 & -0.0001 & 415.9665 & -38.4774 & 125.8297 \\ 9 & -0.0001 & 409.5657 & -72.8370 & 112.2428 \\ 10 & -61.5023 & -0.0000 & -0.0000 & -20.5008 \\ 11 & -0.0001 & -77.4561 & -23.5361 & -33.6641 \\ 12 & -31.2539 & -0.0000 & -0.0000 & -10.4180 \\ 13 & -7.8542 & 0.0001 & -0.0000 & -2.6181 \\ 14 & -0.0001 & 7.1944 & -0.0217 & 2.3909 \\ 15 & -2.5325 & 0.0005 & -0.0000 & -0.8440 \\ 16 & -0.0002 & 13.1177 & 1.2931 & 4.8036 \\ 17 & -0.0003 & 523.8440 & -202.7825 & 107.0204 \\ 18 & -284.3895 & 0.0004 & -0.0001 & -94.7964 \\ 19 & -0.0000 & -197.3428 & -6.0755 & -67.8061 \\ 20 & 1.7584 & -0.0021 & -0.0000 & 0.5854 \\ 21 & 22.0278 & -0.0004 & 0.0000 & 7.3424 \\ 22 & 0.0004 & -111.6004 & -1.8569 & -37.8190 \\ 23 & -0.0000 & 1.3245 & 0.0086 & 0.4444 \\ 24 & -23.3248 & -0.0000 & 0.0000 & -7.7749 \\ 25 & -400.2093 & 0.0000 & -0.0000 & -133.4031 \\ 26 & -0.0005 & -20.6524 & 45.6593 & 8.3355 \\ 27 & -0.0001 & 137.7922 & 1.1886 & 46.3269 \\ 28 & -256.5874 & 0.0001 & -0.0000 & -85.5291 \\ 29 & -84.8443 & 0.0001 & 0.0000 & -28.2814 \\ 30 & -0.0009 & 376.7054 & -35.6188 & 113.6952 \\ 31 & -22.9544 & 0.0002 & 0.0000 & -7.6514 \\ 32 & 0.0000 & 100.1673 & -0.9191 & 33.0827 \\ 33 & 0.0001 & -21.9880 & -1.9936 & -7.9939 \\ 34 & 87.0738 & -0.0002 & 0.0000 & 29.0245\end{array}$




$\begin{array}{lrrrc}35 & -5.1897 & -0.0004 & -0.0000 & -1.7300 \\ 36 & 0.0000 & -23.6591 & -2.7281 & -8.7957 \\ 37 & -49.6429 & -0.0000 & 0.0000 & -16.5476 \\ 38 & 0.0000 & -0.2670 & -25.4151 & -8.5607 \\ 39 & 21.8993 & -0.0000 & 0.0000 & 7.2997 \\ 40 & -0.0206 & 64.8122 & -12.2865 & 17.5017 \\ 41 & -1.5118 & 1.1424 & -0.2058 & -0.1917 \\ 42 & -0.0001 & 33.7044 & -2.2994 & 10.4683 \\ 43 & -200.5989 & -0.0000 & -0.0000 & -66.8663 \\ 44 & -0.0000 & 83.5954 & -31.7765 & 17.2730 \\ 45 & 0.7321 & -0.0001 & -0.0000 & 0.2440 \\ 46 & -0.0000 & -20.7128 & -2.5838 & -7.7656 \\ 47 & 0.0000 & -57.1682 & 10.9661 & -15.4007 \\ 48 & -28.9597 & 0.0000 & 0.0000 & -9.6532 \\ 49 & -0.0000 & -13.8884 & 10.4353 & -1.1510 \\ 50 & -7.1711 & 0.0003 & -0.0000 & -2.3903 \\ 51 & 3.5969 & 0.0000 & 0.0000 & 1.1990 \\ 52 & 0.0000 & 113.7957 & -17.2377 & 32.1860 \\ 53 & -0.0001 & 60.5397 & -24.6761 & 11.9545 \\ 54 & 22.6691 & 0.0001 & -0.0000 & 7.5564 \\ 55 & 0.0000 & 97.0186 & 8.9193 & 35.3126 \\ 56 & 7.0783 & -0.0001 & -0.0000 & 2.3594 \\ 57 & -0.0004 & -74.3967 & 1.9173 & -24.1599 \\ 58 & 9.7192 & 0.0002 & 0.0000 & 3.2398 \\ 59 & -0.0338 & 308.2407 & 139.9717 & 149.3929 \\ 60 & -271.7755 & 0.0304 & 0.0155 & -90.5765\end{array}$

The calculated excited states of conformer 2 of (+)-2

$\begin{array}{lllllll}\text { Excited State } & \text { 1: } & \text { Singlet-A } & 2.8950 \mathrm{eV} & 428.27 \mathrm{~nm} & \mathrm{f}=0.0608 & <\mathrm{S}^{* *} 2>=0.000 \\ \text { Excited State } & \text { 2: } & \text { Singlet-A } & 2.9385 \mathrm{eV} & 421.94 \mathrm{~nm} & \mathrm{f}=0.0014 & <\mathrm{S}^{* *} 2>=0.000 \\ \text { Excited State } & \text { 3: } & \text { Singlet-A } & 2.9475 \mathrm{eV} & 420.64 \mathrm{~nm} & \mathrm{f}=0.0140 & <\mathrm{S}^{* *} 2>=0.000 \\ \text { Excited State } & \text { 4: } & \text { Singlet-A } & 3.0644 \mathrm{eV} & 404.60 \mathrm{~nm} & \mathrm{f}=0.0984 & <\mathrm{S}^{* *} 2>=0.000 \\ \text { Excited State } & \text { 5: } & \text { Singlet-A } & 3.2109 \mathrm{eV} & 386.14 \mathrm{~nm} & \mathrm{f}=0.0037 & <\mathrm{S}^{* *} 2>=0.000 \\ \text { Excited State } & \text { 6: } & \text { Singlet-A } & 3.2799 \mathrm{eV} & 378.01 \mathrm{~nm} & \mathrm{f}=0.0015 & <\mathrm{S}^{* *} 2>=0.000 \\ \text { Excited State } & \text { 7: } & \text { Singlet-A } & 3.4572 \mathrm{eV} & 358.63 \mathrm{~nm} & \mathrm{f}=0.2116 & <\mathrm{S}^{* *} 2>=0.000 \\ \text { Excited State } & \text { 8: } & \text { Singlet-A } & 3.5219 \mathrm{eV} & 352.04 \mathrm{~nm} & \mathrm{f}=0.0588 & <\mathrm{S}^{* *} 2>=0.000 \\ \text { Excited State } & \text { 9: } & \text { Singlet-A } & 3.5408 \mathrm{eV} & 350.16 \mathrm{~nm} & \mathrm{f}=0.0609 & <\mathrm{S}^{* *} 2>=0.000 \\ \text { Excited State } & 10: & \text { Singlet-A } & 3.5781 \mathrm{eV} & 346.51 \mathrm{~nm} & \mathrm{f}=0.0109 & <\mathrm{S}^{* *} 2>=0.000 \\ \text { Excited State } & 11: & \text { Singlet-A } & 3.6798 \mathrm{eV} & 336.93 \mathrm{~nm} & \mathrm{f}=0.0057 & <\mathrm{S}^{* *} 2>=0.000 \\ \text { Excited State } & 12: & \text { Singlet-A } & 3.6876 \mathrm{eV} & 336.22 \mathrm{~nm} & \mathrm{f}=0.0014 & <\mathrm{S} * * 2>=0.000 \\ \text { Excited State } & 13: & \text { Singlet-A } & 3.7941 \mathrm{eV} & 326.79 \mathrm{~nm} & \mathrm{f}=0.0023 & <\mathrm{S}^{* *} 2>=0.000 \\ \text { Excited State } & 14: & \text { Singlet-A } & 3.8027 \mathrm{eV} & 326.04 \mathrm{~nm} & \mathrm{f}=0.0024 & <\mathrm{S}^{* *} 2>=0.000 \\ \text { Excited State } & 15: & \text { Singlet-A } & 3.8543 \mathrm{eV} & 321.67 \mathrm{~nm} & \mathrm{f}=0.0030 & <\mathrm{S}^{* *} 2>=0.000 \\ \text { Excited State } & 16: & \text { Singlet-A } & 3.8843 \mathrm{eV} & 319.19 \mathrm{~nm} & \mathrm{f}=0.0037 & <\mathrm{S}^{* *} 2>=0.000\end{array}$




\begin{tabular}{|c|c|c|c|c|c|c|}
\hline Excited State & 17: & Singlet-A & $3.9379 \mathrm{eV}$ & $314.85 \mathrm{~nm}$ & $\mathrm{f}=0.0868$ & $<\mathrm{S} * * 2>=0.000$ \\
\hline Excited State & 18: & Singlet-A & $4.0554 \mathrm{eV}$ & $305.73 \mathrm{~nm}$ & $\mathrm{f}=0.1337$ & $<\mathrm{S} * * 2>=0.000$ \\
\hline Excited State & 19: & Singlet-A & $4.2167 \mathrm{eV}$ & $294.03 \mathrm{~nm}$ & $\mathrm{f}=0.0336$ & $<\mathrm{S} * * 2>=0.000$ \\
\hline Excited State & 20: & Singlet-A & $4.2408 \mathrm{eV}$ & $292.36 \mathrm{~nm}$ & $\mathrm{f}=0.0008$ & $<\mathrm{S} * * 2>=0.000$ \\
\hline Excited State & 21: & Singlet-A & $4.2552 \mathrm{eV}$ & $291.37 \mathrm{~nm}$ & $\mathrm{f}=0.0010$ & $<\mathrm{S} * * 2>=0.000$ \\
\hline Excited State & 22: & Singlet-A & $4.2620 \mathrm{eV}$ & $290.91 \mathrm{~nm}$ & $\mathrm{f}=0.0275$ & $<\mathrm{S} * * 2>=0.000$ \\
\hline Excited State & 23: & Singlet-A & $4.3489 \mathrm{eV}$ & $285.10 \mathrm{~nm}$ & $\mathrm{f}=0.0027$ & $<\mathrm{S} * * 2>=0.000$ \\
\hline Excited State & 24: & Singlet-A & $4.3928 \mathrm{eV}$ & $282.25 \mathrm{~nm}$ & $\mathrm{f}=0.0016$ & $<\mathrm{S} * * 2>=0.000$ \\
\hline Excited State & 25: & Singlet-A & $4.4147 \mathrm{eV}$ & $280.84 \mathrm{~nm}$ & $\mathrm{f}=0.0985$ & $<\mathrm{S}^{* *} 2>=0.000$ \\
\hline Excited State & 26: & Singlet-A & $4.4503 \mathrm{eV}$ & $278.60 \mathrm{~nm}$ & $\mathrm{f}=0.0110$ & $<\mathrm{S} * * 2>=0.000$ \\
\hline Excited State & 27: & Singlet-A & $4.4647 \mathrm{eV}$ & $277.70 \mathrm{~nm}$ & $\mathrm{f}=0.0264$ & $<\mathrm{S} * * 2>=0.000$ \\
\hline Excited State & 28: & Singlet-A & $4.4986 \mathrm{eV}$ & $275.61 \mathrm{~nm}$ & $\mathrm{f}=0.0616$ & $<\mathrm{S} * * 2>=0.000$ \\
\hline Excited State & 29: & Singlet-A & $4.5272 \mathrm{eV}$ & $273.87 \mathrm{~nm}$ & $\mathrm{f}=0.0042$ & $<\mathrm{S} * * 2>=0.000$ \\
\hline Excited State & 30: & Singlet-A & $4.5531 \mathrm{eV}$ & $272.31 \mathrm{~nm}$ & $\mathrm{f}=0.1047$ & $<\mathrm{S} * * 2>=0.000$ \\
\hline Excited State & 31: & Singlet-A & $4.6150 \mathrm{eV}$ & $268.65 \mathrm{~nm}$ & $\mathrm{f}=0.0008$ & $<\mathrm{S} * * 2>=0.000$ \\
\hline ed State & 32: & Sing & $4.6355 \mathrm{eV}$ & $267.47 \mathrm{~nm}$ & $\mathrm{f}=0.0162$ & $<\mathrm{S} * * 2>=0.000$ \\
\hline Excited State & 33: & Singlet-A & $4.7075 \mathrm{eV}$ & $263.37 \mathrm{~nm}$ & $\mathrm{f}=0.0314$ & $<\mathrm{S} * * 2>=0.000$ \\
\hline Excited State & 34: & Singlet-A & $4.7215 \mathrm{eV}$ & $262.60 \mathrm{~nm}$ & $\mathrm{f}=0.0105$ & $<\mathrm{S} * * 2>=0.000$ \\
\hline Excited State & 35: & Singlet-A & $4.7497 \mathrm{eV}$ & $261.04 \mathrm{~nm}$ & $\mathrm{f}=0.0007$ & $<\mathrm{S} * * 2>=0.000$ \\
\hline Excited State & 36: & Singlet-A & $4.7927 \mathrm{eV}$ & $258.69 \mathrm{~nm}$ & $\mathrm{f}=0.0019$ & $<\mathrm{S} * * 2>=0.000$ \\
\hline Excited State & $37:$ & Singlet-A & $5.1103 \mathrm{eV}$ & $242.62 \mathrm{~nm}$ & $\mathrm{f}=0.0257$ & $<\mathrm{S} * * 2>=0.000$ \\
\hline Excited State & 38: & Singlet-A & $5.1332 \mathrm{eV}$ & $241.53 \mathrm{~nm}$ & $\mathrm{f}=0.0016$ & $<\mathrm{S}^{* *} 2>=0.000$ \\
\hline Excited State & 39: & & $5.1849 \mathrm{eV}$ & $239.13 \mathrm{~nm}$ & $\mathrm{f}=0.0032$ & $<\mathrm{S} * * 2>=0.000$ \\
\hline Excited State & 40: & Singlet-A & $5.1961 \mathrm{eV}$ & $238.61 \mathrm{~nm}$ & $\mathrm{f}=0.0170$ & $<\mathrm{S} * * 2>=0.000$ \\
\hline Excited State & 41: & Singlet-A & $5.1969 \mathrm{eV}$ & $238.57 \mathrm{~nm}$ & $\mathrm{f}=0.0003$ & $<\mathrm{S} * * 2>=0.000$ \\
\hline Excited State & 42: & Singlet-A & & $238.23 \mathrm{~nm}$ & $\mathrm{f}=0.0035$ & $<\mathrm{S} * * 2>=0.000$ \\
\hline Excited State & 43: & Singlet-A & $5.2794 \mathrm{eV}$ & $234.85 \mathrm{~nm}$ & $\mathrm{f}=0.0192$ & $<\mathrm{S} * * 2>=0.000$ \\
\hline Excited State & 44: & Singlet-A & $5.3498 \mathrm{eV}$ & $231.76 \mathrm{~nm}$ & $\mathrm{f}=0.0572$ & $<\mathrm{S} * * 2>=0.000$ \\
\hline Excited State & 45: & Singlet-A & $5.3728 \mathrm{eV}$ & $230.76 \mathrm{~nm}$ & $\mathrm{f}=0.0011$ & $<\mathrm{S} * * 2>=0.000$ \\
\hline Excited State & 46: & Singlet-A & $5.4013 \mathrm{eV}$ & $229.55 \mathrm{~nm}$ & $f=0.0066$ & $<\mathrm{S} * * 2>=0.000$ \\
\hline Excited State & 47: & Singlet-A & $5.4363 \mathrm{eV}$ & $228.07 \mathrm{~nm}$ & $\mathrm{f}=0.0141$ & $<\mathrm{S} * * 2>=0.000$ \\
\hline Excited State & 48: & Singlet-A & $5.4849 \mathrm{eV}$ & $226.05 \mathrm{~nm}$ & $\mathrm{f}=0.0101$ & $<\mathrm{S} * * 2>=0.000$ \\
\hline Excited State & 49: & Singlet-A & $5.5465 \mathrm{eV}$ & $223.54 \mathrm{~nm}$ & $\mathrm{f}=0.0057$ & $<\mathrm{S} * * 2>=0.000$ \\
\hline Excited State & 50: & Singlet-A & $5.5811 \mathrm{eV}$ & $222.15 \mathrm{~nm}$ & $\mathrm{f}=0.0215$ & $<\mathrm{S} * * 2>=0.000$ \\
\hline Excited State & 51: & Singlet-A & $5.5981 \mathrm{eV}$ & $221.48 \mathrm{~nm}$ & $\mathrm{f}=0.0157$ & $<\mathrm{S}^{* *} 2>=0.000$ \\
\hline Excited State & $52:$ & Singlet-A & $5.6075 \mathrm{eV}$ & $221.10 \mathrm{~nm}$ & $\mathrm{f}=0.0139$ & $<\mathrm{S} * * 2>=0.000$ \\
\hline Excited State & 53: & Singlet-A & $5.6397 \mathrm{eV}$ & $219.84 \mathrm{~nm}$ & $\mathrm{f}=0.0099$ & $<\mathrm{S} * * 2>=0.000$ \\
\hline Excited State & 54: & Singlet-A & $5.7374 \mathrm{eV}$ & $216.10 \mathrm{~nm}$ & $\mathrm{f}=0.0004$ & $<\mathrm{S} * * 2>=0.000$ \\
\hline Excited State & 55: & Singlet-A & $5.7417 \mathrm{eV}$ & $215.94 \mathrm{~nm}$ & $\mathrm{f}=0.0404$ & $<\mathrm{S} * * 2>=0.000$ \\
\hline Excited State & $56:$ & Singlet-A & $5.7738 \mathrm{eV}$ & $214.73 \mathrm{~nm}$ & $\mathrm{f}=0.0002$ & $<\mathrm{S} * * 2>=0.000$ \\
\hline Excited State & 57: & Singlet-A & $5.8228 \mathrm{eV}$ & $212.93 \mathrm{~nm}$ & $\mathrm{f}=0.0050$ & $<\mathrm{S} * * 2>=0.000$ \\
\hline Excited State & 58: & Singlet-A & $5.8368 \mathrm{eV}$ & $212.42 \mathrm{~nm}$ & $\mathrm{f}=0.0001$ & $<\mathrm{S} * * 2>=0.000$ \\
\hline Excited State & 59: & Singlet-A & $5.9172 \mathrm{eV}$ & $209.53 \mathrm{~nm}$ & $\mathrm{f}=0.0806$ & $<\mathrm{S}^{* *} 2>=0.000$ \\
\hline Excited State & 60: & Singlet-A & $5.9222 \mathrm{eV}$ & $209.36 \mathrm{~nm}$ & $\mathrm{f}=0.0258$ & $<\mathrm{S} * * 2>=0.000$ \\
\hline
\end{tabular}

